Article

\title{
Trends in synthetic biology in the bioeconomy of non-food- competing biofuels
}

\author{
Antônio Luiz Fantinel1, Rogério Margis², Edson Talamini' ${ }^{3, *}$ and Homero Dewes ${ }^{4}$
}

1 Interdisciplinary Center for Studies and Research in Agribusiness - CEPAN, Universidade Federal do Rio Grande do Sul - UFRGS, Porto Alegre, RS, Brazil; tonifantinel@gmail.com

2 Department of Biophysics, Universidade Federal do Rio Grande do Sul - UFRGS, Porto Alegre, RS, Brazil; rogerio.margis@ufrgs.br

3 Department of Economics and International Relations - DERI, Faculty of Economics - FCE, and Interdisciplinary Center for Studies and Research in Agribusiness - CEPAN, Universidade Federal do Rio Grande do Sul - UFRGS, Porto Alegre, RS, Brazil; edson.talamini@ufrgs.br

4 Department of Biophysics, and Interdisciplinary Center for Studies and Research in Agribusiness - CEPAN, Universidade Federal do Rio Grande do Sul - UFRGS, Porto Alegre, RS, Brazil; hdewes@ufrgs.br

* Correspondence: edson.talamini@ufrgs.br

\begin{abstract}
Despite the acknowledged relevance of renewable energy sources, biofuel production supported by food-related agriculture has faced severe criticism. One way to minimize the considered negative impacts is the use of sources of non-food biomass or wastes. Synthetic biology (SB) embraces a promising complex of technologies for biofuel production from non-edible and sustainable raw materials. Therefore, it is pertinent to identify the global evolution of investments, concepts, and techniques underlying the field in support of policy formulations for sustainable bioenergy production. We mapped the SB scientific knowledge related to biofuels using software that combines information visualization methods, bibliometrics, and data mining algorithms. The United States and China have been the leading countries in developing SB technologies. Technical University of Denmark and Tsinghua University are the institutions with higher centrality and have played prominent roles besides UC-Los Angeles and Delft University Technology. We identified six knowledge clusters under the terms: versatile sugar dehydrogenase, redox balance principle, sesquiterpene production, Saccharomyces cerevisiae, recombinant xylose-fermenting strain, and Clostridium saccharoperbutylacetonicum N1-4. The emerging trends refer to specific microorganisms, processes, and products. Yarrowia lipolytica, Oleaginous yeast, E. coli, Klebsiella pneumoniae, Phaeodactylum tricornutum, and Microalgae are the most prominent microorganisms, mainly from the year 2016 onwards. Anaerobic digestion, synthetic promoters, and genetic analysis appear as the most relevant platforms of new processes. Improved biofuels, bioethanol, and N-butanol are at the frontier of the development of SB-derived products. Synthetic biology is a dynamic interdisciplinary field in environmentally friendly bioenergy production pushed by growing social concerns and the emergent bioeconomy.
\end{abstract}

Keywords: microbial production; bioethanol; biodiesel; SynB; food security; information science; scientometry.

\section{Introduction}

Increasing concerns regarding the over-dependence on fossil fuels have spurred demand for agrofuel production, leading to competition for agricultural land and changes in land use [1,2,3]. Ethanol produced from sugarcane in Brazil [4], and corn from the US [5], are the leading commodities within the global renewable fuel supply chain, followed by the production of soybean-derived biodiesel in Brazil [6,7], and rapeseedderived biodiesel in Germany [8]. Growth in biofuel production supported by foodrelated agriculture has caused the biobased economy to face severe criticism in the global economy discussion [9]. 
One way to minimize these negative impacts is the use of sources of non-food biomass or wastes. Among the various biomasses with potential for production of bioenergy, lignocellulosic biomass from agricultural and forest residues [10], algae [11,12], municipal waste [10], industrial effluents, and animal waste are gaining attention as possible feedstocks due to low cost [13], and high production [14]. However, high costs and the relatively low efficiency of available enzymes and microorganisms for raw residual biomass transformation into biofuels are relevant challenges currently faced by industries [15,16]. To assist in transforming this biomass into biofuels, new biotechnological roads are needed, including those emerging from synthetic biology. This includes the design and construction of new live factories, the accurate design of new metabolic pathways, and the generation of effective enzymes $[17,18]$.

Synthetic biology is an emerging field $[19,20,21]$, harmoniously combining science and engineering to design and build new biological parts, non-natural devices or systems, and to redesign existing biological systems for the generation of useful products [22]. This new area of knowledge has become a putative, sustainable alternative for the generation of bioenergy using low-cost bioeconomy substrates $[23,24,25]$. The use of synthetic biology tools and approaches provides the opportunity for fermentation and the manufacture of products not naturally generated in large quantities in native microorganisms [26,27].

In the currently used biofuel production processes, the yeast Saccharomyces cerevisiae dominates the fermentation of ethanol from sugar-based feedstocks. However, they are not natural degraders of arabinose [28], and xylose [29], requiring the use of engineering ways to make these sugars accessible in the fermentation process [30,31]. Another alternative route for alcohol production is through the bacterium Escherichia coli due to its ability to use pentoses and hexoses [32]. Several bacteria [33], yeasts [34,35], algae $[11,36,37]$, and cyanobacteria [38], have the potential to produce fatty acids precursors for biofuels. Non-native Yarrowia lipolytica yeast presents an industrial potential for fatty acidproducing platforms from cheap and renewable routes [39]. Microalgae have enormous potential for biofuel production due to their high cell growth rate and can be grown on marginal lands $[40,11,15]$, and wastewater $[41,42]$ thus reducing the need for nutrients for the growth of photosynthetic cells.

Other microorganisms are the object of studies to overcome the difficulties of those model cell factories. Photosynthetic organisms [43] that directly use $\mathrm{CO} 2$ and the methanotrophic bacteria [44] that use natural gas as the source of carbon are examples. Synthetic biology contributes significantly to achieving the production of non-foodrelated biofuels using new biological systems [45,46,47], and also offering the possibility to make controlled biological processes competitive and valuable for human and animal well-being [48].

These new advances may cause significant changes in the socio-economic, agricultural, and technological framing of bioenergy [49,50,51]. Furthermore, there is worldwide concern regarding the development of the globally integrated framework for bioenergy, its environmental impact, and its relevance in the bioeconomy $[52,53,54,55]$. Alternative sources of feedstock for bioenergy not competing with the production of food are increasingly necessary, as they relate to concerns regarding climate change, food, and energy security in different nations. The use of alternative feedstocks requires new technological processes that pose new industrial challenges, research investments, and their consequences in terms of intellectual property, production, and market access. In this context, we wanted to assess the geopolitical, institutional, technological trends in the research in synthetic biology related to biofuels $[56,57]$ towards strategic fundaments for local and globally integrated bioenergy policies.

Synthetic biology is a promising technological platform for producing biofuels from alternative feedstocks [58]. The production of biofuels is at the core of the current discussions on the bioeconomy [55,59]. In this work, we carried out a scientometric analysis of the dynamics of a scientific development relevant for strategy and policy formulations towards a world focused on social and environmentally sustainable, renewable energy sources. 


\section{Results}

2.1 Articles, reviews, and citations on synthetic biology-related biofuels

The publications on biofuels, synthetic biology, and metabolic engineering between 1999 and 2018 are shown in Figure 1.

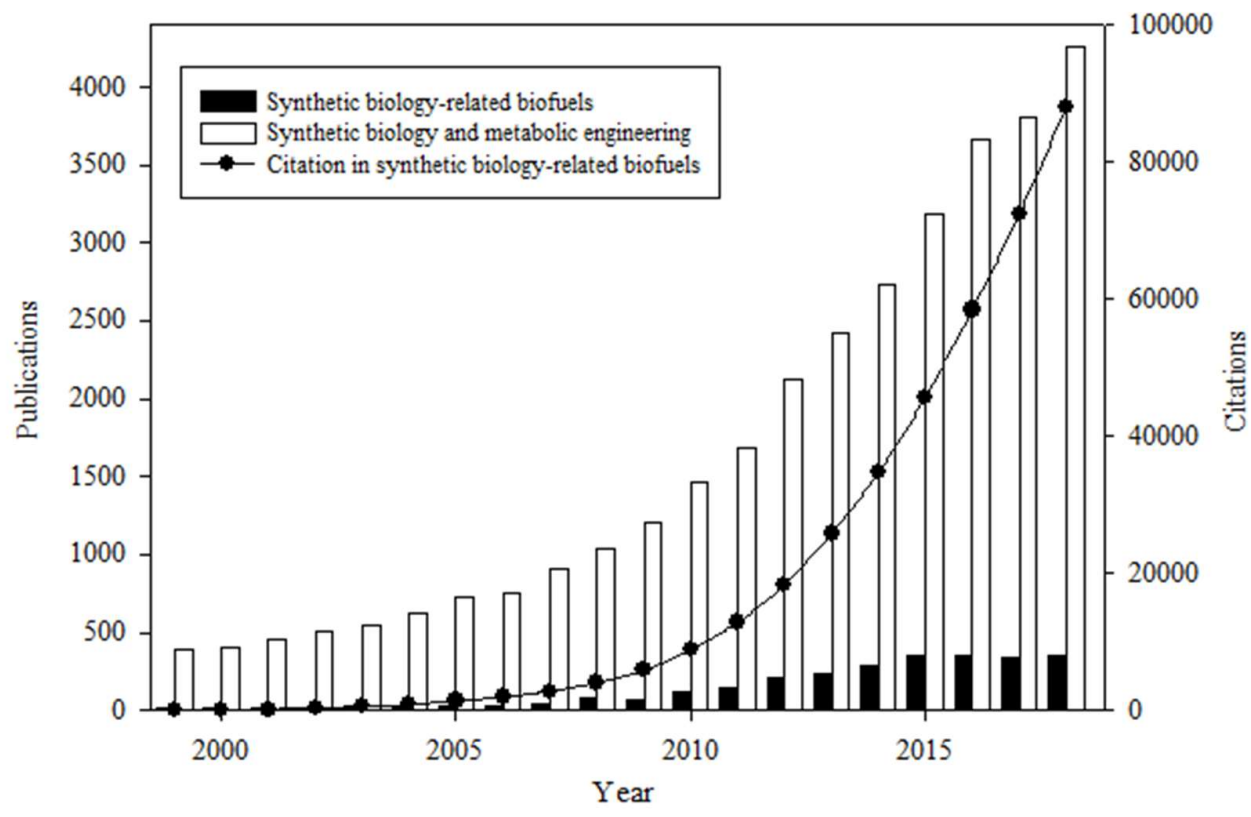

Figure 1. Synthetic biology, metabolic engineering, and biofuel-related articles and reviews according to Web of Science (1999-2018).

The 2,718 scientific publications on biofuels related to synthetic biology (black bars), can be divided into two phases. The first phase (1999-2014) is characterized by rapid scientific development. The second phase (years 2015-2018) indicates that research in this area has entered a stable stage. In 2018, the last year of review, we retrieved 349 publications. The scientific production was accompanied by a substantial increase in the number of citations (black line), around 87,855 citations in the accumulated period, expressing the continued importance of the subject within the scientific context. The 2,718 scientific publications in synthetic biology-related biofuels represent $9 \%$ of all publications on synthetic biology and metabolic engineering in that period (white bars) (Figure 1).

\subsection{Changes in the knowledge on synthetic biology-related biofuels}

Two Dual-Map Overlays on synthetic biology-related biofuels are shown in Figure 2. The Dual-Map Overlays function used in this research reveals the scientific standard disciplines and the evolution of publications on synthetic biology-related biofuels in the global map of the scientific literature. The articles in the network of journals are located on the left side of the base map. The references cited in the respective articles are in the network of journal citations on the right side of the base map, grouped using the z-score function. The $\mathrm{z}$-score is the distance from the mean of a given data point, expressed as the number of standard deviations [60].

The first ten years of analysis (1999-2008) are shown in Figure 2a. Line thickness is proportional to the z-score value. Publications on synthetic biology-related biofuels appear mainly in the interdisciplinary field (citing map) of "molecular/biology/immunology" (orange citation links). The knowledge base of this disciplinary field (cited map) is mainly related to the disciplines of "molecular/biology/genetics", and "environment/toxicology/nutrition". As shown in Figure 2b, a new interdisciplinary field (citing map) emerged from 2009 to 2018, entitled "veterinary/animal/science" (yellow citation links). 
Like for "molecular/biology/immunology" (orange citation links) the knowledge (base map cited) comes from the disciplines of "molecular/biology/genetics" and "environment/toxicology/nutrition".

a

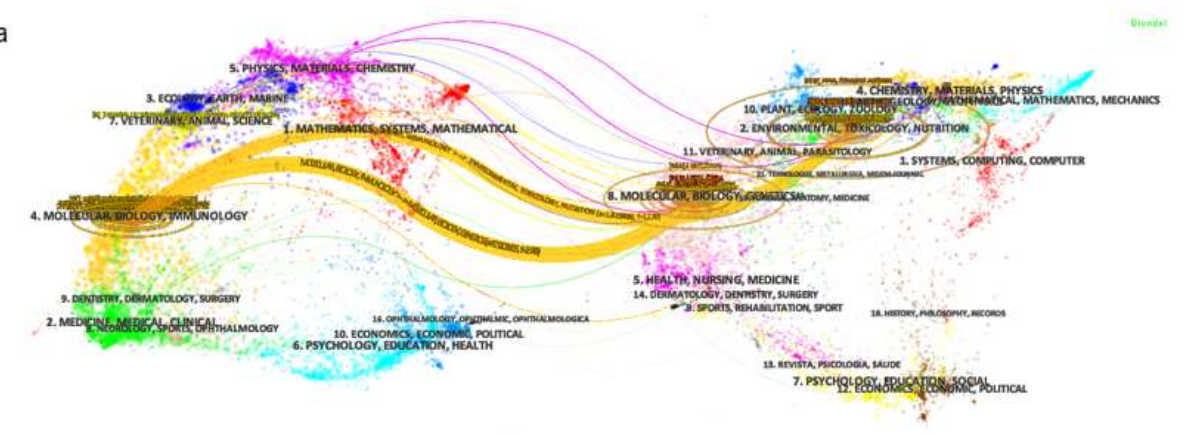

b

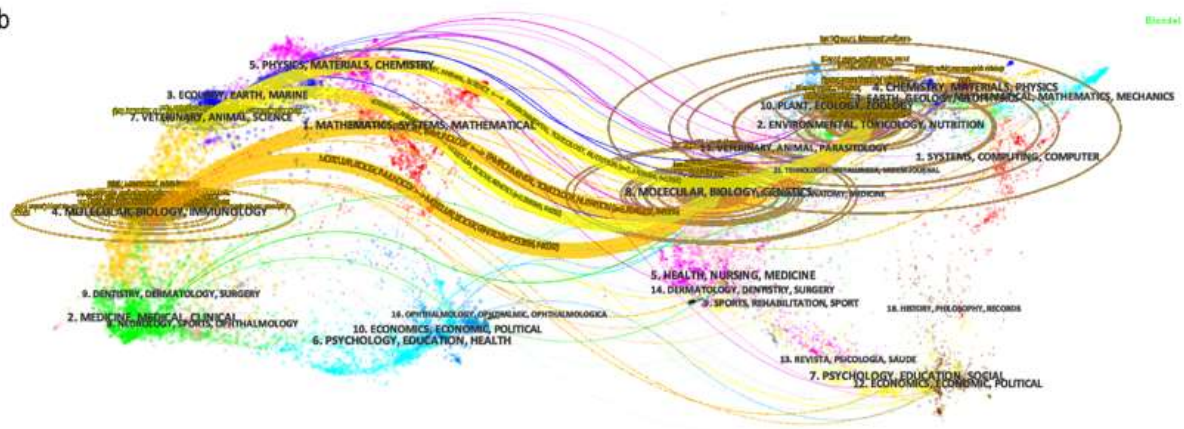

Figure 2. Dual-Map Overlays showing the interplay of scientific disciplines in the interdisciplinary field of research on synthetic biology-related biofuels.

The journals Applied and Environmental Microbiology, Applied Microbiology, and Biotechnology, Proceedings of the National Academy of Sciences (PNAS), Metabolic Engineering, and Biotechnology and Bioengineering are the most influential knowledge sources of synthetic biology-related biofuels research.

\subsection{Worldwide distribution of research on synthetic biology-related biofuels}

The countries co-citation map in research on synthetic biology-related biofuels shows 51 nodes and 57 links (Figure 3). Each node represents a country. This network of 51 countries has a modularity of 0.9638 , a mean silhouette value of 0.6688 , and a density of 0.0414 , indicating that the links between the various countries are not very close, so there is little cooperation between them. The key countries were identified based on the frequency of publications, centrality, and bursts of citation. The US with 1,083 and China with 492 publications were the most active countries.

Purple circles, in Figure 3, mark nodes with high betweenness centrality, quantifying the importance of the node position in a network [61,62]. Among them, Sweden presents the highest centrality (0.83), followed by France (0.58), and Germany (0.48). Sweden's betweenness centrality encompasses Germany, England, and Switzerland. The strongest France cooperation ties are with the US, Canada, and Poland. Germany's strongest cooperation ties are with Sweden, Denmark, and Italy. Red rings on nodes are citation bursts and highlight emerging specialties [62]. By burst detection in-country analysis, we found that Germany (6.15), Canada (5.76), and Switzerland (3.62) have shown citation bursts. 


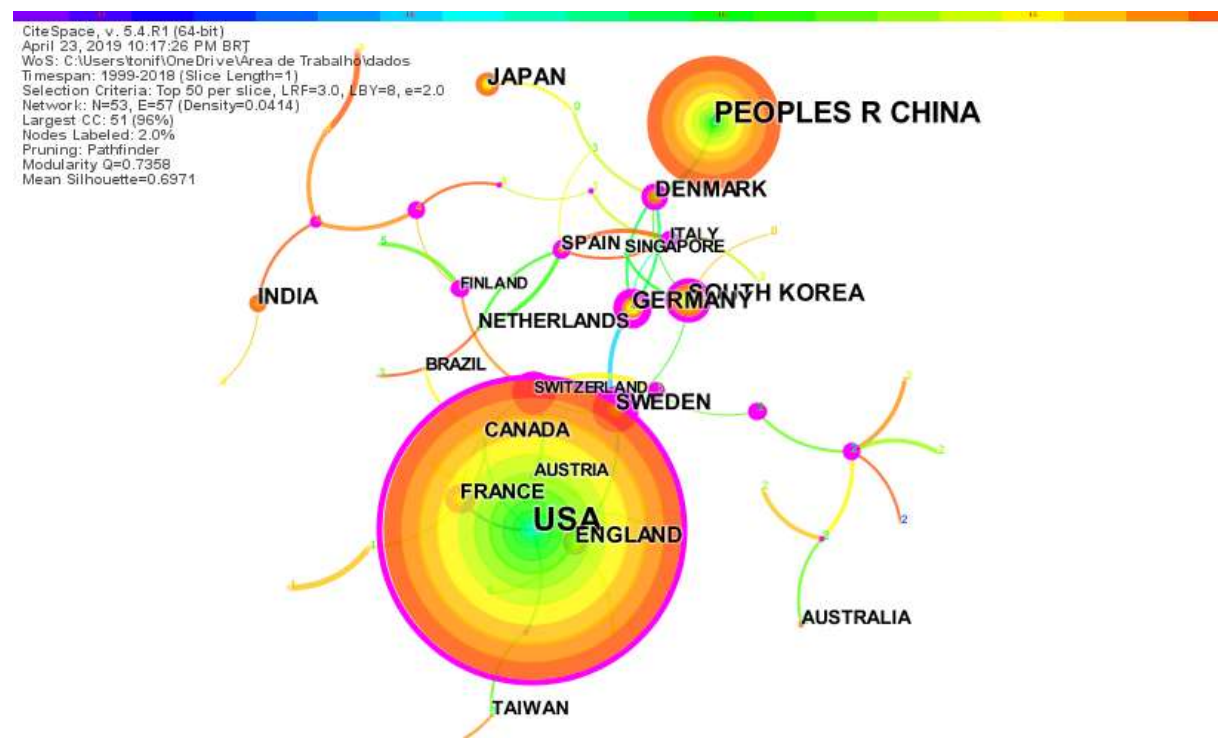

Figure 3. Countries co-citation map in research on synthetic biology-related biofuels.

\subsection{Institutions co-citation network}

The institutions co-citation map in research on synthetic biology-related biofuels shows 279 nodes and 260 links (Figure 4). Each node represents a research institution. This network of institutions has modularity of 0.9638 , an average silhouette value of 0.6688 , and a density of 0.0067 , which indicates little cooperation between them. The core research institutions identified based on the frequency of publications, centrality, and bursts of citations are the Chinese Academy of Sciences with 123 publications and the University of California Berkeley-US with 105 publications.

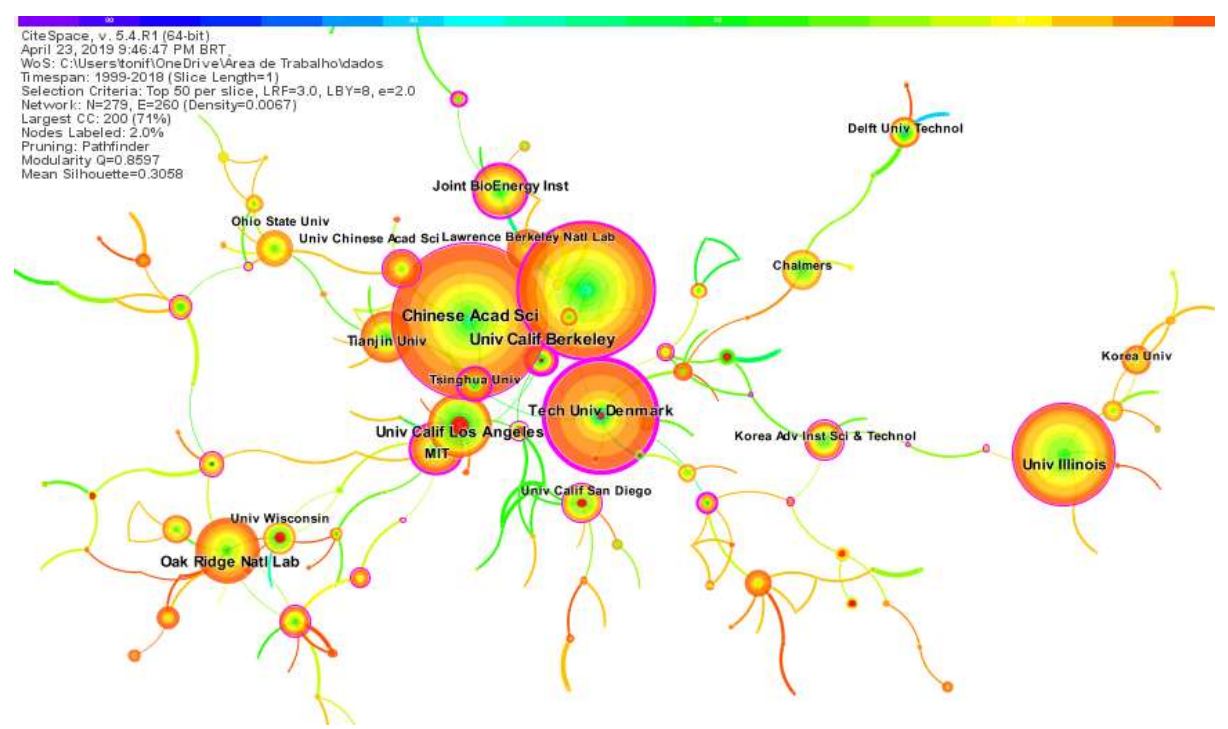

Figure 4. Institutions' co-citation map in research on synthetic biology-related biofuels

In Figure 4, purple circles mark nodes with high betweenness centrality [61], showing the importance of a node position in a network [62]. The Technical University of Denmark has the highest centrality (0.39), with strong cooperation ties with other institutions, namely Chalmers University of Technology, UC-San Diego, and UC-Berkeley. The second most collaborative institution is Tsinghua University (0.24), with strong ties of cooperation with the Chinese Academy of Sciences, Tianjin University, and Technical University 
of Denmark. Red rings on nodes are citation bursts and highlight emerging specialties [62]. By burst detection, we found that UC-Los Angeles (8.87), Delft University Technology (4.62), and Technical University of Denmark (4.31) have played prominent roles in the field.

\subsection{Clusters co-citation map of authors and research topics on synthetic biology-related biofuels}

We generated a landscape of the authors co-citation sets and their respective research topics on synthetic biology-related biofuels. The co-citation network presents modularity of 0.9638 , suggesting that the nodes are clearly defined within each cluster, and a mean silhouette value of 0.6688 , indicating a satisfactory partition [63]. The network density of 0.0414 indicates that there is little or almost no cooperation between the authors. The most productive authors in the time span surveyed were Jens Nielsen of the Chalmers University of Technology, Jay Keasling of UC - Berkeley, and James C. Liao of UC - Los Angeles, with respectively 49, 47, and 39 publications. In Figure 5, purple circles mark the nodes with high betweenness centrality, given the importance of the node position in a network, with Jay Keasling standing out.

The searched authors formed eleven knowledge clusters (Figure 5). Clusters with green areas are the oldest. The yellow areas represent the most recent ones. Table 1 shows the six largest groups in terms of size (number of references included), labels extracted from titles, abstracts, the average year of articles cited, and the coverage of citations. Each cluster is summarized with a list of phrases selected from the abstracts of the articles that mention at least one member of the cluster and are weighted by the algorithm log-likelihood ratio (LLR) [62].

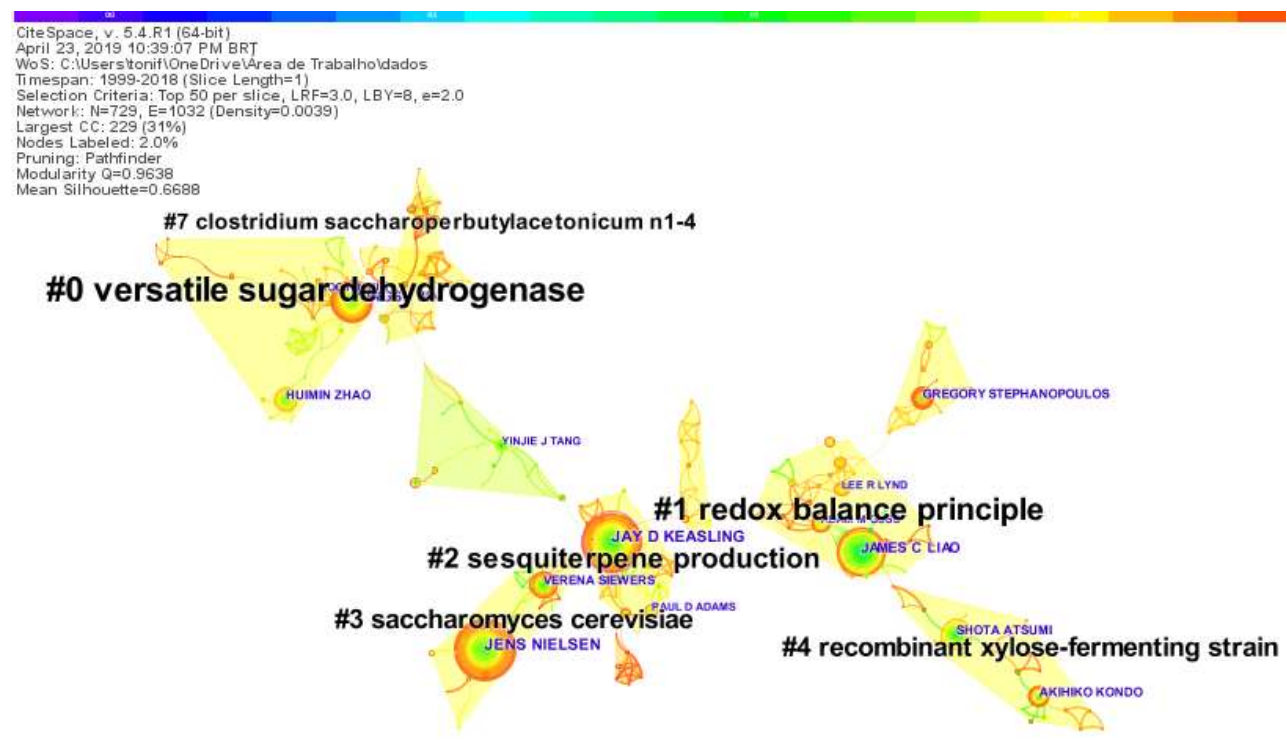

Figure 5. Co-citation map of authorship and specific topics in the research on synthetic biology related to biofuels.

The largest cluster (\#0), which is labeled "versatile sugar dehydrogenase" contains 41 references (Table 1 ), with a silhouette value of 1 , indicating to be a cluster highly consistent or similar in terms of content searched [63]. The references were published mainly around the year 2014. This knowledge cluster contains studies on l-arabonate and d-galactonate production by expressing a versatile sugar dehydrogenase in metabolically engineered E. coli [64], direct bioconversion of d-xylose to 1,2,4-butanetriol in an engineered E. coli [65], engineered Rhodosporidium toruloides for increased lipid production [66], and gene amplification for accelerating cellobiose utilization in engineered S. cerevisiae [67]. Each of these articles covered not less than $5 \%$ of the 41 references. 
The second-largest cluster (\#1), labeled as "redox balance principle" contains 34 references (Table 1), with a silhouette value is 0.911 . The references were published mainly around the year 2014. This knowledge cluster contains studies on high-throughput, in vivo selection platform for NADPH-dependent reactions based on redox balance principles [68], engineering Coenzyme A (CoA) [69,70], ethanol production in Clostridium thermocellum via deregulated nitrogen metabolism [71], and perturbed sulfur metabolism [72]. Each of these articles covered not less than $3 \%$ of the 34 references.

Table 1. Knowledge clusters in the research of biofuels related to synthetic biology.

\begin{tabular}{|c|c|c|c|c|c|}
\hline Cluster & Size & Silhouette & Label (LLR) & Year & $\begin{array}{l}\text { Citation } \\
\text { Coverage }\end{array}$ \\
\hline$\# 0$ & 41 & 1 & $\begin{array}{l}\text { Versatile Sugar Dehydrogenase (219.06, 1.0E-4); D-Galactonate } \\
\text { Production (219.06, 1.0E-4); Engineered Saccharomyces cerevisiae (204.24, } \\
\text { 1.0E-4) }\end{array}$ & 2014 & {$[64,65,66,67]$} \\
\hline$\# 1$ & 34 & 0.911 & $\begin{array}{l}\text { Redox Balance Principle (197.02, 1.0E-4); Nadph-Dependent Reaction } \\
(197.02,1.0 \mathrm{E}-4) \text {; Vivo Selection Platform (197.02, 1.0E-4) }\end{array}$ & 2014 & {$[68,69,70,71,72$} \\
\hline$\# 2$ & 29 & 0.946 & $\begin{array}{l}\text { Sesquiterpene Production (313.39, 1.0E-4); Principal Component } \\
\text { Analysis (209.89, 1.0E-4); Characterizing Strain Variation }(189.08,1.0 \mathrm{E}-4) \text {; }\end{array}$ & 2014 & {$[73,74]$} \\
\hline$\# 3$ & 25 & 0.977 & $\begin{array}{l}\text { Saccharomyces cerevisiae (360.26, 1.0E-4); Co-Factor Supply (207.54, } \\
\text { 1.0E-4); Alpha-Santalene Production }(207.54,1.0 \mathrm{E}-4)\end{array}$ & 2014 & {$[75,76,77]$} \\
\hline$\# 4$ & 24 & 0.984 & $\begin{array}{l}\text { Recombinant xylose-fermenting strain (191.79, 1.0E-4); Metabolic } \\
\text { Pathway Engineering }(191.79,1.0 \mathrm{E}-4) \text {; Formic Acid Tolerance (191.79, } \\
\text { 1.0E-4) }\end{array}$ & 2014 & {$[78,79,80,81]$} \\
\hline$\# 7$ & 16 & 0.984 & $\begin{array}{l}\text { Clostridium saccharoperbutylacetonicum n1-4 (275.82, 1.0E-4); Model } \\
\text { Diatom Phaeodactylum tricornutum (197.67, 1.0E-4); Potential Regulatory } \\
\text { Role }(197.67,1.0 \mathrm{E}-4)\end{array}$ & 2015 & {$[82,83,84,85]$} \\
\hline
\end{tabular}

The third-largest cluster (\#2), labeled “sesquiterpene production" contains 29 references (Table 1), with a silhouette value is 0.946 . The references were published around the year 2014. This knowledge cluster contains studies on the analysis of proteomics as a tool to direct metabolic engineering [86], and characterization of E. coli using a Multi-Omics base [74]. Each of these articles covered not less than $4 \%$ of the 29 references.

The fourth-largest cluster (\#3), labeled "redox balance principle" contains 25 references (Table 1), with a silhouette value is 0.977 . The references were published around the year 2014. This knowledge cluster contains studies on cell factories for $\alpha$-santalene production [75], lactate production by cyanobacteria [76], and reconstruction and evaluation of the synthetic bacterial MEP pathway in S. cerevisiae [77]. Each of these articles covered not less than $3 \%$ of the 25 references.

The fifth-largest cluster (\#4), labeled "redox balance principle" contains 24 references (Table 1), with a silhouette value is 0.984 . The references were published around the year 2014. This knowledge cluster contains studies on d-lactic acid production by $S$. cerevisiae [78], metabolomics approach [80], yeast strain metabolically engineered for tolerance to fermentation inhibitors [81], and 2,3-Butanediol (BDO) production by S. cerevisiae [79]. Each of these articles covered not less than $3 \%$ of the 24 references.

The sixth-largest cluster (\#7) is the most recent one among all the clusters shown in Figure 5. It is labeled "Clostridium saccharoperbutylacetonicum N1-4". It contains 16 references, with a silhouette value of 0.984 . The references were published around the year 2015 (Table 1). This knowledge cluster contains studies on plastidial triacylglycerol 
synthesis, the potential regulatory role of AGPAT in the model diatom Phaeodactylum tricornutum [82], glycerol and neutral lipid production in the oleaginous marine diatom $P$. tricornutum [83], antisense knockdown of pyruvate dehydrogenase kinase for neutral lipid accumulation in P. tricornutum [84], and genome editing in C. saccharoperbutylacetonicum N1-4 with the CRISPR-Cas9 system [85]. Each of these articles covered not less than $3 \%$ of the 16 references.

\subsection{Papers with the strongest citation bursts on synthetic biology-related biofuels}

The key papers with the citation bursts of the research on synthetic biology-related biofuels are shown in Table 2. The citation burst's function was used to highlight documents with the strongest bursts. The blue lines represent the periods analyzed (1999 to 2018), and the red lines indicate the start and the final years of the respective document's citation burst $[87,62]$. Those are articles have markedly influenced the scientific development of the field. The first two articles with more citation bursts address metabolic engineering and its tools [88]. They present a review of the metabolic pathways used to produce advanced biofuels regardless of feedstock and host, together with data-based approaches and synthetic biology for host and path optimization. They project the future of biofuel production. Atsumi et al. [46] used these metabolic engineering tools in E. coli to produce higher alcohols from glucose. The third article, by Gibson et al. [89], presents an isothermal, single-reaction method for assembling multiple overlapping DNA molecules by the concerted action of a 5' exonuclease, a DNA polymerase, and a DNA ligase.

Table 2. Top scientific articles with the strongest citation bursts in the research on synthetic biology-related biofuels

\begin{tabular}{llllll}
\hline Articles & Year & Strength & Begin & End & 1999 - 2018 \\
\hline Peralta-Yahya et al. [88] & 2012 & 371.738 & 2013 & 2018 & \\
Atsumi et al. [46] & 2008 & 367.477 & 2010 & 2016 & \\
Gibson et al. [89] & 2009 & 270.418 & 2013 & 2018 & \\
Atsumi et al. [43] & 2008 & 269.481 & 2010 & 2014 & \\
Shen et al. [90] & 2011 & 264.006 & 2012 & 2018 & \\
Connor and Atsumi [91] & 2009 & 256.165 & 2011 & 2016 & \\
Tai and Stephanopoulos [92] & 2013 & 216.846 & 2014 & 2018 & \\
Dellomonaco et al. [93] & 2011 & 214.931 & 2012 & 2018 & \\
Zhang et al. [94] & 2012 & 212.798 & 2013 & 2018 & \\
Runguphan and Keasling [95] & 2014 & 210.905 & 2015 & 2018 & \\
\hline
\end{tabular}

The fourth and fifth article with more citation bursts presents the potential of E. coli bacteria in the production of butanol. Atsumi et al. [45] designed a synthetic pathway in E. coli to produce 1-butanol. For the authors, the success in the production of 1-butanol from the engineering of $E$. coli opens the possibility of using non-native organisms, easily manipulated to produce 1-butanol [45]. Shen et al. [90] constructed a modified clostridial 1-butanol pathway in $E$. coli to provide an irreversible reaction catalyzed by trans-enoylcoenzyme A (CoA) reductase (Ter), and created NADH and acetyl-CoA driving forces to direct the flux.

The sixth article presents the potential of the cyanobacterium Synechococcus elongatus. Connor and Atsumi [91] genetically engineered the strain S. elongatus PCC7942 to produce isobutyraldehyde and isobutanol directly from CO2, and increased productivity by overexpression of ribulose 1,5-bisphosphate carboxylase/oxygenase (Rubisco). The combined use of genetic engineering in Y. lipolytica aiming to significantly increase the production of lipids, from Tai and Stephanopoulos [92] is the seventh article with the highest burst 
strength. The authors demonstrated the ability of $Y$. lipolytica to produce lipids, and the metabolic engineering effects of two important steps in the lipid synthesis pathway, which acts on the flow deviation for lipid synthesis and creates the driving force for the synthesis of triglyceride (TAG). In the eighth position is the article by Dellomonaco et al. [93]. The authors demonstrated that a functional reversal of the $\beta$-oxidation cycle can be used as a metabolic platform for the synthesis of alcohols and carboxylic acids with various chain lengths and functionalities.

In the ninth position, Zhang et al. [94] presented a dynamic sensor-regulator (DSRS) to produce products based on fatty acids in E. coli, with the potential for biodiesel production. In the tenth position is the article by Runguphan and Keasling [95]. The authors designed the yeast $S$. cerevisiae to produce biofuels derived from fatty acids, and chemicals from simple sugars.

\subsection{Emerging trends and new developments in the research on synthetic biology-related biofuels}

Using keyword-bursts, we analyzed the new trends in the field. The burst of a keyword means that it has received special attention from academic circles in a specific period $[87,62]$. Table 3 presents the length and intensity of the top twenty keyword-bursts. These high burst values indicate that the aspects these words referred to are hot topics and research boundaries in synthetic biology-related biofuels.

The most intense word is Y. lipolytica due to its enormous industrial potential for the future bio-refinery platform [39]. Research on Y. lipolytica and oleaginous yeast aims to increase the production of fatty acids from cheap and renewable routes [39] in a context more adaptable to industrial applications. With the emergence of synthetic biology, new approaches such as proteomic analysis [96] and gene overexpression [97] are being applied to this yeast. Recently, the CRISPR-Cas9 tool was successfully applied in Y. lipolytica for genomic-oriented manipulation [98].

The anaerobic digestion processes in microbial communities have ample potential for bioenergy, as they allow the use of low-cost feedstocks, such as wastewater and biomass, to produce biofuels. Thus, different omic tools have been applied in Coprothermobacter proteolyticus [99], and Pseudomonas putida [100].

The production process of bioethanol is the one with the best technical development among microbial biofuels. This technology is expected to be mature in the coming years. Advances in metagenomics [101], orthogonal communication systems [102], metaproteomics [103], metabolomics [96], and metabolic engineering [104], are improving the microbial fermentation processes and increasing yields in the production of cellulosic bioethanol [105].

Most industrial applications using microorganisms as living factories make use of lignocellulosic biomass or agricultural waste [106], relating this word to a hot research topic. The co-fermentation of different sugars from lignocellulosic biomass and residues allows the ethanol production processes to become economically viable [107]. However, microorganisms potentially usable in these fermentative processes are not naturally adaptable to extreme industrial conditions [108], given the low productivity, low-stress resistance, and accumulation of by-products due to the recalcitrance of biomass [73]. To overcome these limitations, several genetic engineering strategies in microorganisms have incorporated the use of synthetic promoters in the study of gene function [109], and transcription factors (TF) as regulators of metabolic pathways to increase the production of biofuel molecules from lignocellulosic biomass [110,111].

Table 3. The top 20 keywords with the strongest bursts of citation in the research on synthetic biology-related biofuels as published in the most recent years of the period of analysis

\begin{tabular}{llccccc}
\hline Classes & Keywords & Strength & Year & Begin & End & 1999-2018 \\
\hline \multirow{2}{*}{ Organisms } & Yarrowia lipolytica & 160.346 & 1999 & 2016 & 2018 & \\
& Oleaginous yeast & 82.659 & 1999 & 2016 & 2018 &
\end{tabular}




\begin{tabular}{llllllll} 
& E. coli & 54.287 & 1999 & 2014 & 2018 & \\
& Klebsiella pneumoniae & 54.065 & 1999 & 2016 & 2018 & \\
& Phaeodactylum tricornutum & 51.463 & 1999 & 2016 & 2018 & \\
& Microalgae & 45.048 & 1999 & 2016 & 2018 & \\
\cline { 2 - 2 } & 83.171 & 1999 & 2016 & 2018 & \\
& Anvanced biofuel & 82.808 & 1999 & 2014 & 2018 & \\
& Adoethanol & 82.265 & 1999 & 2015 & 2018 & \\
& Lignocellulosic biomass & 62.484 & 1999 & 2015 & 2018 & \\
& Synthetic promoters & 58.377 & 1999 & 2015 & 2018 & \\
& Biorefinery & 43.827 & 1999 & 2016 & 2018 & \\
Processes & Genetic sequencing & 43.701 & 1999 & 2016 & 2018 & \\
and & Nitrogen starvation & 39.342 & 1999 & 2015 & 2018 & \\
products & Wastewater & 38.613 & 1999 & 2016 & 2018 & \\
& Mevalonate pathways & 38.257 & 1999 & 2016 & 2018 & \\
& Lipids accumulation & 33.134 & 1999 & 2016 & 2018 & \\
& Biotechnology & 31.641 & 1999 & 2016 & 2018 & \\
& N-butanol & 5.198 & 1999 & 2016 & 2018 & \\
& Transcription factor & 4.045 & 1999 & 2015 & 2018 & \\
\hline
\end{tabular}

E. coli is a gram-negative bacterium considered the most popular workhorse for industrial production due to complete knowledge of its genomics. Also, E. coli is a gene donor [101] for new functions in the metabolic pathway in a series of other microorganisms [112]. The main disadvantages of this bacterial culture are the narrow $\mathrm{pH}$ growth range (6.0-8.0) and the fact that ethanol is not a central product of this bacterium. Among other synthetic biology approaches, research is focused on the development of synthetic promoters [113] for targeting new mevalonate pathways for multiple cellular processes [114,73].

Another gram-negative bacterium with biotechnological potential is Klebsiella pneumoniae. It is widely used in microbial consortia to improve tolerance to xylose [115]. K. pneumoniae is nutritionally versatile with numerous native pathways useful for biofuel production. It is a well-known and industrially important platform for chemicals derived from various sugars [116]. Proteomic [117] and differential metabolomic [85] analysis provide new routes and perspectives to produce industrial metabolites such as n-butanol [111].

It is not new that microalgae have enormous biosynthetic potential under adverse physiological conditions [11,37], being recognized as a propitious source for the sustainable production of bio-based fuels $[25,118]$. P. tricornutum is a model microalga with biotechnological potential for future biorefineries [41]. Microalgae are photosynthetic microorganisms capable of lipid accumulation by transforming $\mathrm{CO} 2$ and heat into chemical energy at scales larger than those of terrestrial plants [110,119]. Besides, they can use wastewater [41,42], which reduces the need for other valuable nutrients. Therefore, the research focuses on the genomics of the metabolism related to the formation and accumulation of lipids $[120,121]$. The performance of new promoters under nitrogen starvation conditions is also studied in this photosynthetic microorganism [122].

The keyword-bursts analyzed and discussed here provide an overview of the main trends and emerging topics in the research focused on synthetic biology related to nonfood biofuels.

\section{Discussion and future perspectives}


We analyzed the geopolitical and institutional scenario and examined the content of the scientific literature on synthetic biology related to biofuels. Our results highlight the evolution of concepts and emergences that may assist in assessing scientific development and in suggesting future policy formulations for a world focused on a sustainable bioeconomy [59].

The scientific evolution observed is mainly due to advances in the metabolic manipulation of microorganisms $[123,124,125,126,127]$, and by the reduction of cost of DNA sequencing and synthesis [128,121]. Scientific publications have undergone significant changes in their theoretical and methodological background. These changes in disciplinary foundations have evolved to respond to the new needs of world society, becoming increasingly multidisciplinary.

We showed that the geopolitical distribution of publications originates mainly from high-income countries, such as the US. The US achieved great advantage and influence in the field of synthetic biology related to biofuels, as noticed not only by the number of publications but also by the collaboration with countries of high centrality and by government investments in synthetic biology [120,129]. This technology offers notable benefits not only to produce biofuels but also for other applications. In the US, synthetic biology is seen as a technological path for providing a healthier life, less dependence on fossil resources, new manufacturing processes, increased productivity in the agricultural sector, and the creation of jobs through the development of bio-based markets [130]. Institutions in the US are at the top of the ranking in terms of contribution and influence.

We looked at the development and the academic influence of the authors, according to the number of publications and centrality of their respective work. Each author presented in Table 4 is responsible for at least 20 articles. It indicates the researchers who actively investigate synthetic biology in the production of biofuels or related fields.

Based on the authors' co-citations (Table 1), we pointed out some characteristics of the research network. The intellectual base presents topics with an interdisciplinary character. Their link is the metabolic and genetic tools to improve microorganisms in bioethanol and fatty acids production from biomass and low-cost waste.

Analyzing the articles-bursts and keywords-bursts, we identified the evolution of the conceptual base in the field [62] to understand the trends at critical research points. The domains of knowledge verified in the analysis of articles-burst went from complex analysis to methodologies aimed at low-cost gene synthesis and assembly of synthetic paths. The design and the construction or modification of new molecular and cellular matrices for synthetic paths/modules including promoters, RNAs, and scaffolding [45] lead to new industrial processes to produce metabolites such as bioethanol and fatty acids [131].

Similarly, keyword-bursts analysis was used to determine the new frontiers and scientific trends. In our study, the emerging trends were mainly focused on the research and development of oilseed yeast $Y$. lipolytica, gram-negative bacteria like E. coli and K. pneumoniae, microalgae, and $P$. tricornutum to produce advanced biofuels, with emphasis on bioethanol and n-butanol from lignocellulosic biomass and wastewater [18]. Promoters, transcription factors, and genetic sequencing tools are used for the regulation of metabolic pathways to increase lipid accumulation and to produce biofuel molecules in those microorganisms. The high explosion values indicate that the aspects to which these keywords belong are still topics and frontiers for research on biofuels in the future. Also, related to these terms, the others are meta-transcriptomics, meta-genomics, assimilation metabolism, proteomic analysis, genetic and metabolic engineering in their application to transform living factories into biorefineries.

Given the availability of genetic and molecular tools to redesign existing native pathways or create new synthetic ones, $E$. coli is the best choice for producing biofuels from renewable energy sources [32]. However, product toxicity is one of the main bottlenecks in achieving the maximum production of biofuels. With that in mind, Xu et al. [132] used host deformation engineering to alleviate the solvent toxicity in fermentation. Likewise, new synthetic promoters in E. coli provide better biochemicals and biofuels production by 
fine-tuning gene expression levels [113]. Bervoets et al. [102] present a set of orthogonal expression systems based on Bacillus subtilis sigma heterologous factors that may contribute to the assembly of more complex synthetic genetic systems in the future. In addition to being used as a living factory, due to complete knowledge of its genomics, E. coli is a gene donor [101] for new functions in the metabolic pathways of a series of other microorganisms [112].

In an attempt to overcome the obstacles to greater use of biomass, new research in biomanufacturing based on genomics in microorganisms, enzymes, and new metabolic pathways has started a new era of discoveries with industrial potential $[133,18,134]$. An example is $Y$. lipolytica research aimed at increasing the production of fatty acids from cheap and renewable routes [39], in a context more adaptable to industrial applications. We can add new genome editing tools based on the CRISPR-Cas system, leading to greater viability in industrial microbial systems producing consumer goods $[135,136]$ and allowing the production of lipids with industrial potential for future biorefinery platforms. The use of microalgae has enormous energy potential, given the possibility of transforming $\mathrm{CO} 2$ and heat into chemical energy at scales much larger than those produced by terrestrial plants [110], without competing with food production. $P$. tricornutum is a strain with significant biotechnological potential for future photosynthetic biorefineries [41]. New species of microalgae, including Scenedesmium sp NBRI012, have high productivity of biomass, carbohydrates, and lipid content. After the production of bio-hydrogen, residual biomass with high lipid content can be used as a source to produce biodiesel [110].

At the same time, lignocellulosic biomass, agricultural residues, and wastewater have been emphasized as feedstock to produce advanced biofuels using synthetic living factories. Thus, bioprocesses that use live factories are turning their attention to new substrates, leaving aside the use of glucose, for greater use of non-food biomass, $\mathrm{CO}_{2}$, and low-cost waste as carbon sources, drawing attention to the potential of a bioeconomy regimen [59]. The potential of lignocellulosic biomass provides a new path to produce biofuels that do not compete with food because it is cheaper and available in large quantities $[15,137,138]$. In Brazil, as a pertinent example, the territorial extension and the regional edaphoclimatic characteristics make possible the intensive production of biomass for industrial biotechnology at a lower cost, compared to other countries that prospect for synthetic microbial cells. Concomitantly, there is also the possible use of agro-industrial byproducts and residues as substrate [139]. Brazil, in the future, may become the largest producer of products of biobased origin. Another candidate substratum of great potential is the use of wastewater because the use of this cheap and abundant resource can significantly minimize input and energy costs in biofuels production processes [140].

Different engineering strategies, like automation, regulation, and reengineering of cellular machines can be tested on hosts in a relatively short time and at a lower experimental cost. However, while enabling predictive approaches to assist in the research and development of biomolecules in various synthetic pathways at the destination host [134], we still face a knowledge gap that does not allow us to project cells in an environment in a truly predictable way that results in a lineage with increased cell yield. New cellular systems capable of using different carbon sources are needed to produce biofuels [141], including genetic parts specifically related to biosensors and inducible promoters [142]. Emphasis is put on the development of tools for a better understanding of the metabolism of fatty acids [131], and for genomic expression in oleaginous yeasts [143], allowing the use of cheaper and renewable substrates in industrial applications. For microalgae, new tools are needed that can improve nuclear manipulation and the construction of a synthetic genetic network on a genome scale, thus being able shortly to increase the biomass rate and $\mathrm{CO}_{2}$ fixation capacity by these microorganisms [36,118]. Metabolic engineering in microalgae may improve control over lipid and growth pathways, resulting in more reproducible and predictable systems compared to wild-type strains [37].

On the other hand, there are political, economic, and social issues. Given the lower productivity and high costs of bioproduction, the use of microorganisms as living factories is still difficult to compete with conventional industries [144]. Factors such as the 
current relatively low prices of fossil fuels and the devaluation of biofuels by developing countries make this technology lose space in the bioenergy market [145]. In the case of Brazil, despite the earlier policies for the development of biofuels, governmental inputs for fossil oil production, like the ocean pre-salt oil initiative in 2007 , biofuels have been so far left behind. Thus, appropriate government policies are needed to increase interest in the production of advanced biofuels using live factories, so that this technology can achieve market success in the coming years.

Having overcome the challenges, synthetic biology could reach and cover not only the biofuel supply chain but also other areas that form agribusiness, with greater added value [146]. The synthetic biology tools applied to microorganisms offer the possibility of producing chemicals for agricultural production that can increase agricultural productivity [147], give greater nutritional value to agricultural products [148], and benefit the environment [149]. Bio-factories can also be used to make substances currently produced by plants for food [150], medicine [151,152], among other sectors. Thus, the diversity of compounds and molecules that can be produced using synthetic living factories can revolutionize the production of biomolecules for routine and common use, entering a new era of bioeconomy, with the development of bioproducts of high economic value $[153,154,155]$. We look forward to synergistic, institutional efforts to support the development of organic production systems economically viable, without aggravating land [156], and water use [157] and limiting the environmental impact of human activities while expanding the industry into new frontiers of bioenergy and other bio-based products.

\section{Materials and Methods}

A scientometric analysis was applied to evaluate the geopolitical, institutional, and technological trends in synthetic biology-related biofuels from sustainable, non-land use, and non-food competing resources using the software CiteSpace. The software combines information visualization methods, bibliometrics, and data mining algorithms in an interactive visualization tool for pattern extraction in citation data $[158,62]$. CiteSpace has been used in technological forecasting studies on many topics, from patents $[159,160]$ to consumer innovation resistance [161]

\subsection{Research data}

Articles and reviews on synthetic biology-related biofuels were collected using the Web of Science (WOS) - Clarivate Analytics (https://apps.webofknowledge.com). To reach almost the whole set of publications related to the focus themes, we applied a lexical expansion [162] for rescuing as many relevant publications as possible. For comprehensive coverage of the field of synthetic biology, we used different terms in the analysis [163]. We also included terms related to metabolic engineering, the technical approach for the proper functioning of the projected living factories [164,165].

Unlike previous research that aimed to analyze the literature probed by single-core terms such as "synthetic biology" [166] or "biotechnology" [167], this study uses combined keywords for retrieving the synergy of different research fields to produce non-food biofuels. In this way, we expanded the knowledge retrieved and gained a more comprehensive scientific categorization of the subject. Thus, the query used in this research contains two main search strategies combined using Boolean operators. The first strategy directly addresses the concepts and types of non-food-biofuels. The second research strategy addresses the concepts and approaches related to synthetic biology, metabolic engineering, and conceptual variations. Thus, the strategy for retrieving publications in the WOS-database by the terms selected was as follows: TOPIC: (biofuel* OR ethanol OR biogas OR "alcohol fuel" OR bioenergy OR "microbial oil" OR "microbial biofuel" OR biodiesel OR biobutanol OR butanol OR bioethanol OR biohydrogen OR methanol OR bioalcohol OR "fatty acid esters" OR farnesene OR "bio-diesel" OR "bio diesel" OR biooil OR "bio-oil") AND TOPIC: ("synthetic biology" OR "synthetic pathways" OR "metabolic 
engineering" OR "metabolic pathways" OR "synthetic circuits" OR "synthetic systems" OR "synthetic genomics" OR "synthetic genome" OR "synthetic genes" OR "synthetic nets").

The language of recovery was English. The search period was from 1999 up to 2018. The search resulted in 2,863 publications (articles and reviews). Of those, we excluded 145 documents unrelated to the research topic, resulting in 2,718 original publications: 2,057 articles, and 661 reviews.

\subsection{Data analysis}

We imported the full dataset of 2,718 publications into CiteSpace and set the timeslicing as "1999-2018". We selected the 50 most cited references for each year in the chosen period to map the co-citation networks. The Pathfinder network scaling was adopted to prune each network and remove the redundant links between nodes [62,63]. We then analyze countries, institutions, funding agencies, and authors based on the co-citation network. We used the co-citation network of the authors to visualize the research groups and detect notable developments in the scientific field through clusters.

The method focuses on the interrelations between a co-citation cluster member and their citers [63]. The articles and keywords were analyzed using the Kleinberg burst detection algorithm [87]. Besides, we used the dual-map overlay tool to analyze the evolution of the scientific literature in biofuels related to synthetic biology. Dual-map overlay of journals provides a global map of the growth of literature at the academic level [60], shows the relationship between the distributions of cited journals and citing journals in the literature, and reveals the evolution of the distribution with the time [168].

\subsection{Networks properties}

The network properties were measured using structural and temporal metrics. Structural metrics include network density, modularity, silhouette, and centrality of intermediation.

The density of the network $d$ was used to express the degree of proximity in the relationships between each node. Low density denotes that the links between the different nodes are not very close, so there is little cooperation between them $[169,170]$. The modularity $Q$ was used to measure the extent to which a network can be divided into independent blocks, ranging from 0 to 1 . The closer to 1 , the more structured the network will be [63]. The silhouette metric developed by Rousseeuw [171] was used to estimate the uncertainty involved in identifying the nature of a cluster. The value of the silhouette of a cluster ranges from -1 to 1 . The value of 1 represents a perfect separation from other clusters, the highest level of homogeneity $[62,63]$. Freeman's centrality of intermediation was used to highlight possible central points of the paradigm shift over time [61]. It measures the degree to which the node is part of the paths that connect an arbitrary pair of nodes in the network, with a value $\geq 0.1$. The high values of the centrality of intermediation are identifiers of potentially revolutionary scientific publications, as well as gatekeepers on social networks [61,62].

As a temporal metric we use Kleinberg's burst detection algorithm [87]. This tool analyzes whether a specific frequency function has had statistically significant fluctuations over a given period. Thus, this rupture detection algorithm is adapted to identify new research front concepts $[87,62]$.

\section{Conclusions}

New research approaches on biofuels expand bioeconomy into new forms of energy production using sustainable, renewable biological substrates. The transition toward a bio-based economy is associated with biofuels that do not use food-related feedstocks by combining approaches and tools of synthetic biology and evolutionary engineering in industrial bioprocesses. In this bibliometric study, policymakers and stakeholders may 
access relevant, detailed information on a research trend and emerging technology that will shape the bioeconomy as a new fundament of society.

Author Contributions: Conceptualization, H.D., R.M., A.L.F. and E.T.; methodology, A.LF. and E.T.; software, A.L.F.; validation, R.M., H.D. and A.L.F.; formal analysis, H.D., R.M., A.L.F. and E.T.; investigation, A.L.F.; resources, R.M. and E.T.; data curation, A.L.F. and E.T.; writing-original draft preparation, A.L.F. and H.D.; writing-review and editing, H.D., R.M., and E.T.; visualization, A.L.F.; supervision, R.M. and H.D.; project administration, A.L.F. and H.D.; funding acquisition, R.M. and E.T. All authors have read and agreed to the published version of the manuscript.

Funding:This research was funded by National Council for Scientific and Technological Development (CNPq), grants numbers 309586/2019-4, 303956/2019-4, and 141259/2016-7. The APC was funded by authors.

Institutional Review Board Statement: Not applicable.

Acknowledgments: A.L.F., R.M., and E.T. are grateful for supporting received from the National Council for Scientific and Technological Development-CNPq, and Coordenação de Aperfeiçoamento de Pessoal de Nível Superior-CAPES.

Conflicts of Interest: The authors declare no conflict of interest.

\section{References}

1. Balat, M. Potential alternatives to edible oils for biodiesel production - A review of current work. Energy Convers. Manag. 2011, 52, 1479-1492, doi:10.1016/j.enconman.2010.10.011.

2. Coleman, M.A.; Goold, H.D. Harnessing synthetic biology for kelp forest conservation 1. J. Phycol. 2019, 55, 745751, doi:10.1111/jpy.12888.

3. French, K.E. Harnessing synthetic biology for sustainable development. Nat. Sustain. 2019, 2, 250-252, doi:10.1038/s41893-019-0270-x.

4. Rudorff, B.F.T.; Aguiar, D.A.; Silva, W.F.; Sugawara, L.M.; Adami, M.; Moreira, M.A. Studies on the Rapid Expansion of Sugarcane for Ethanol Production in São Paulo State (Brazil) Using Landsat Data. Remote Sens. 2010, 2, 1057-1076, doi:10.3390/rs2041057.

5. Pimentel, D.; Patzek, T.W. Ethanol Production Using Corn, Switchgrass, and Wood: Biodiesel Production Using Soybean and Sunflower. Nat. Resour. Res. 2005, 14, 65-76, doi:10.1007/s11053-005-4679-8.

6. Bergmann, J..; Tupinambá, D..; Costa, O.Y..; Almeida, J.R..; Barreto, C..; Quirino, B.. Biodiesel production in Brazil and alternative biomass feedstocks. Renew. Sustain. Energy Rev. 2013, 21, 411-420, doi:10.1016/j.rser.2012.12.058.

7. Souza, S.P.; Seabra, J.E.A.; Nogueira, L.A.H. Feedstocks for biodiesel production: Brazilian and global perspectives. Biofuels 2018, 9, 455-478, doi:10.1080/17597269.2017.1278931.

8. Ayres, A. Germany's water footprint of transport fuels. Appl. Energy 2014, 113, 1746-1751, doi:10.1016/j.apenergy.2013.05.063.

9. Nanda, S.; Mohammad, J.; Reddy, S.N.; Kozinski, J.A.; Dalai, A.K. Pathways of lignocellulosic biomass conversion to renewable fuels. Biomass Convers. Biorefinery 2014, 4, 157-191, doi:10.1007/s13399-013-0097-z.

10. Ribeiro, B.E.; Quintanilla, M.A. Transitions in biofuel technologies: An appraisal of the social impacts of cellulosic ethanol using the Delphi method. Technol. Forecast. Soc. Change 2015, 92, 53-68, doi:10.1016/j.techfore.2014.11.006.

11. Wang, M.-Y.; Fang, S.-C.; Chang, Y.-H. Exploring technological opportunities by mining the gaps between science and technology: Microalgal biofuels. Technol. Forecast. Soc. Change 2015, 92, 182-195, doi:10.1016/j.techfore.2014.07.008. 
12. Anto, S.; Mukherjee, S.S.; Muthappa, R.; Mathimani, T.; Deviram, G.; Kumar, S.S.; Verma, T.N.; Pugazhendhi, A. Algae as green energy reserve: Technological outlook on biofuel production. Chemosphere 2020, 242, 125079, doi:10.1016/j.chemosphere.2019.125079.

13. Zhang, Y.-H.P. A sweet out-of-the-box solution to the hydrogen economy: is the sugar-powered car science fiction? Energy Environ. Sci. 2009, 2, 272, doi:10.1039/b818694d.

14. Zhu, P.; Abdelaziz, O.Y.; Hulteberg, C.P.; Riisager, A. New synthetic approaches to biofuels from lignocellulosic biomass. Curr. Opin. Green Sustain. Chem. 2020, 21, 16-21, doi:10.1016/j.cogsc.2019.08.005.

15. Trumbo, J.L.; Tonn, B.E. Biofuels: A sustainable choice for the United States' energy future? Technol. Forecast. Soc. Change 2016, 104, 147-161, doi:10.1016/j.techfore.2015.11.015.

16. Srivastava, N.; Srivastava, M.; Ramteke, P.W.; Mishra, P.K. Synthetic Biology Strategy for Microbial Cellulases. In New and Future Developments in Microbial Biotechnology and Bioengineering; Elsevier, 2019; pp. $229-238$.

17. Kalluri, U.C.; Yin, H.; Yang, X.; Davison, B.H. Systems and synthetic biology approaches to alter plant cell walls and reduce biomass recalcitrance. Plant Biotechnol. J. 2014, 12, 1207-1216, doi:10.1111/pbi.12283.

18. Prasad, R.K.; Chatterjee, S.; Mazumder, P.B.; Gupta, S.K.; Sharma, S.; Vairale, M.G.; Datta, S.; Dwivedi, S.K.; Gupta, D.K. Bioethanol production from waste lignocelluloses: A review on microbial degradation potential. Chemosphere 2019, 231, 588-606, doi:10.1016/j.chemosphere.2019.05.142.

19. Mukherji, S.; van Oudenaarden, A. Synthetic biology: understanding biological design from synthetic circuits. Nat. Rev. Genet. 2009, 10, 859-871, doi:10.1038/nrg2697.

20. Shapira, P.; Kwon, S.; Youtie, J. Tracking the emergence of synthetic biology. Scientometrics 2017, 112, 1439-1469, doi:10.1007/s11192-017-2452-5.

21. Porter, A.L.; Chiavetta, D.; Newman, N.C. Measuring tech emergence: A contest. Technol. Forecast. Soc. Change 2020, 159, 120176, doi:10.1016/j.techfore.2020.120176.

22. Benner, S.A.; Sismour, A.M. 10.1038/nrg1637. Nat. Rev. Genet. 2005, 6, 533-543, doi:10.1038/nrg1637.

23. Philp, J. Balancing the bioeconomy: supporting biofuels and bio-based materials in public policy. Energy Environ. Sci. 2015, 8, 3063-3068, doi:10.1039/C5EE01864A.

24. Aro, E.-M. From first generation biofuels to advanced solar biofuels. Ambio 2016, 45, 24-31, doi:10.1007/s13280015-0730-0.

25. Ribeiro, B.; Shapira, P. Anticipating governance challenges in synthetic biology: Insights from biosynthetic menthol. Technol. Forecast. Soc. Change 2019, 139, 311-320, doi:10.1016/j.techfore.2018.11.020.

26. Wehrs, M.; Tanjore, D.; Eng, T.; Lievense, J.; Pray, T.R.; Mukhopadhyay, A. Engineering Robust Production Microbes for Large-Scale Cultivation. Trends Microbiol. 2019, 27, 524-537, doi:10.1016/j.tim.2019.01.006.

27. Xu, N.; Wei, L.; Liu, J. Recent advances in the applications of promoter engineering for the optimization of metabolite biosynthesis. World J. Microbiol. Biotechnol. 2019, 35, 33, doi:10.1007/s11274-019-2606-0.

28. Buschke, N.; Schäfer, R.; Becker, J.; Wittmann, C. Metabolic engineering of industrial platform microorganisms for biorefinery applications - Optimization of substrate spectrum and process robustness by rational and evolutive strategies. Bioresour. Technol. 2013, 135, 544-554, doi:10.1016/j.biortech.2012.11.047.

29. Moysés, D.; Reis, V.; Almeida, J.; Moraes, L.; Torres, F. Xylose Fermentation by Saccharomyces cerevisiae: Challenges and Prospects. Int. J. Mol. Sci. 2016, 17, 207, doi:10.3390/ijms17030207.

30. Lee, W.-H.; Jin, Y.-S. Evaluation of Ethanol Production Activity by Engineered Saccharomyces cerevisiae Fermenting Cellobiose through the Phosphorolytic Pathway in Simultaneous Saccharification and Fermentation of Cellulose. J. Microbiol. Biotechnol. 2017, 27, 1649-1656, doi:10.4014/jmb.1705.05039.

31. Bracher, J.M.; Verhoeven, M.D.; Wisselink, H.W.; Crimi, B.; Nijland, J.G.; Driessen, A.J.M.; Klaassen, P.; van Maris, A.J.A.; Daran, J.-M.G.; Pronk, J.T. The Penicillium chrysogenum transporter PcAraT enables high-affinity, 
glucose-insensitive l-arabinose transport in Saccharomyces cerevisiae. Biotechnol. Biofuels 2018, 11, 63, doi:10.1186/s13068-018-1047-6.

32. Koppolu, V.; Vasigala, V.K. Role of Escherichia coli in Biofuel Production. Microbiol. Insights 2016, 9, MBI.S10878, doi:10.4137/MBI.S10878.

33. Sherkhanov, S.; Korman, T.P.; Clarke, S.G.; Bowie, J.U. Production of FAME biodiesel in E. coli by direct methylation with an insect enzyme. Sci. Rep. 2016, 6, 24239, doi:10.1038/srep24239.

34. Wenning, L.; Ejsing, C.S.; David, F.; Sprenger, R.R.; Nielsen, J.; Siewers, V. Increasing jojoba-like wax ester production in Saccharomyces cerevisiae by enhancing very long-chain, monounsaturated fatty acid synthesis. Microb. Cell Fact. 2019, 18, 49, doi:10.1186/s12934-019-1098-9.

35. Bergman, A.; Vitay, D.; Hellgren, J.; Chen, Y.; Nielsen, J.; Siewers, V. Effects of overexpression of STB5 in Saccharomyces cerevisiae on fatty acid biosynthesis, physiology and transcriptome. FEMS Yeast Res. 2019, 19, doi:10.1093/femsyr/foz027.

36. Jagadevan, S.; Banerjee, A.; Banerjee, C.; Guria, C.; Tiwari, R.; Baweja, M.; Shukla, P. Recent developments in synthetic biology and metabolic engineering in microalgae towards biofuel production. Biotechnol. Biofuels 2018, 11, 185, doi:10.1186/s13068-018-1181-1.

37. Arora, N.; Tripathi, S.; Poluri, K.M.; Pruthi, V. Advanced Gene Technology and Synthetic Biology Approaches to Custom Design Microalgae for Biodiesel Production. In Microalgae Biotechnology for Development of Biofuel and Wastewater Treatment; Springer Singapore: Singapore, 2019; pp. 147-175.

38. Bellefleur, M.P.A.; Wanda, S.-Y.; Curtiss, R. Characterizing active transportation mechanisms for free fatty acids and antibiotics in Synechocystis sp. PCC 6803. BMC Biotechnol. 2019, 19, 5, doi:10.1186/s12896-019-0500-3.

39. Markham, K.A.; Alper, H.S. Synthetic Biology Expands the Industrial Potential of Yarrowia lipolytica. Trends Biotechnol. 2018, 36, 1085-1095, doi:10.1016/j.tibtech.2018.05.004.

40. Chisti, Y. Biodiesel from microalgae beats bioethanol. Trends Biotechnol. 2008, 26, 126-131, doi:10.1016/j.tibtech.2007.12.002.

41. Davis, R.W.; Siccardi, A.J.; Huysman, N.D.; Wyatt, N.B.; Hewson, J.C.; Lane, T.W. Growth of mono- and mixed cultures of Nannochloropsis salina and Phaeodactylum tricornutum on struvite as a nutrient source. Bioresour. Technol. 2015, 198, 577-585, doi:10.1016/j.biortech.2015.09.070.

42. Popko, J.; Herrfurth, C.; Feussner, K.; Ischebeck, T.; Iven, T.; Haslam, R.; Hamilton, M.; Sayanova, O.; Napier, J.; Khozin-Goldberg, I.; et al. Metabolome Analysis Reveals Betaine Lipids as Major Source for Triglyceride Formation, and the Accumulation of Sedoheptulose during Nitrogen-Starvation of Phaeodactylum tricornutum. PLoS One 2016, 11, e0164673, doi:10.1371/journal.pone.0164673.

43. Atsumi, S.; Higashide, W.; Liao, J.C. Direct photosynthetic recycling of carbon dioxide to isobutyraldehyde. Nat. Biotechnol. 2009, doi:10.1038/nbt.1586.

44. Strong, P.J.; Xie, S.; Clarke, W.P. Methane as a Resource: Can the Methanotrophs Add Value? Environ. Sci. Technol. 2015, 49, 4001-4018, doi:10.1021/es504242n.

45. Atsumi, S.; Cann, A.F.; Connor, M.R.; Shen, C.R.; Smith, K.M.; Brynildsen, M.P.; Chou, K.J.Y.; Hanai, T.; Liao, J.C. Metabolic engineering of Escherichia coli for 1-butanol production. Metab. Eng. 2008, doi:10.1016/j.ymben.2007.08.003.

46. Atsumi, S.; Hanai, T.; Liao, J.C. Non-fermentative pathways for synthesis of branched-chain higher alcohols as biofuels. Nature 2008, doi:10.1038/nature06450.

47. Rude, M.A.; Schirmer, A. New microbial fuels: a biotech perspective. Curr. Opin. Microbiol. 2009, 12, 274-281, doi:10.1016/j.mib.2009.04.004.

48. Singh, B.K.; Trivedi, P. Microbiome and the future for food and nutrient security. Microb. Biotechnol. 2017, 10, 50- 
53, doi:10.1111/1751-7915.12592.

49. Narnoliya, L.K.; Jadaun, J.S.; Singh, S.P. Management of Agro-industrial Wastes with the Aid of Synthetic Biology. In; 2018; pp. 11-28.

50. Paul, S.; Dutta, A. Challenges and opportunities of lignocellulosic biomass for anaerobic digestion. Resour. Conserv. Recycl. 2018, 130, 164-174, doi:10.1016/j.resconrec.2017.12.005.

51. Dahmen, N.; Lewandowski, I.; Zibek, S.; Weidtmann, A. Integrated lignocellulosic value chains in a growing bioeconomy: Status quo and perspectives. GCB Bioenergy 2019, 11, 107-117, doi:10.1111/gcbb.12586.

52. Talamini, E.; Eduardo Caldarelli, C.; Wubben, E.F.M.; Dewes, H. The composition and impact of stakeholders' agendas on US ethanol production. Energy Policy 2012, 50, doi:10.1016/j.enpol.2012.08.005.

53. Talamini, E.; Wubben, E.F.M.; Domingos Padula, A.; Dewes, H. Scanning the macro-environment for liquid biofuels: A comparative analysis from public policies in Brazil, United States and Germany. J. Strateg. Manag. 2013, 6, doi:10.1108/17554251311296558.

54. Gomes, J.; Dewes, H. Disciplinary dimensions and social relevance in the scientific communications on biofuels. Scientometrics 2017, 110, 1173-1189, doi:10.1007/s11192-016-2233-6.

55. Befort, N. Going beyond definitions to understand tensions within the bioeconomy: The contribution of sociotechnical regimes to contested fields. Technol. Forecast. Soc. Change 2020, 153, 119923, doi:10.1016/j.techfore.2020.119923.

56. Clomburg, J.M.; Gonzalez, R. Biofuel production in Escherichia coli: the role of metabolic engineering and synthetic biology. Appl. Microbiol. Biotechnol. 2010, 86, 419-434, doi:10.1007/s00253-010-2446-1.

57. Berla, B.M.; Saha, R.; Immethun, C.M.; Maranas, C.D.; Moon, T.S.; Pakrasi, H.B. Synthetic biology of cyanobacteria: unique challenges and opportunities. Front. Microbiol. 2013, 4, doi:10.3389/fmicb.2013.00246.

58. Zilberman, D.; Kim, E.; Kirschner, S.; Kaplan, S.; Reeves, J. Technology and the future bioeconomy. Agric. Econ. 2013, 44, 95-102, doi:10.1111/agec.12054.

59. Jonsson, R.; Rinaldi, F.; Pilli, R.; Fiorese, G.; Hurmekoski, E.; Cazzaniga, N.; Robert, N.; Camia, A. Boosting the EU forest-based bioeconomy: Market, climate, and employment impacts. Technol. Forecast. Soc. Change 2021, 163, 120478, doi:10.1016/j.techfore.2020.120478.

60. Chen, C.; Leydesdorff, L. Patterns of connections and movements in dual-map overlays: A new method of publication portfolio analysis. J. Assoc. Inf. Sci. Technol. 2014, 65, 334-351, doi:10.1002/asi.22968.

61. Freeman, L.C. Centrality in social networks conceptual clarification. Soc. Networks 1978, 1, 215-239, doi:10.1016/0378-8733(78)90021-7.

62. Chen, C. CiteSpace II: Detecting and visualizing emerging trends and transient patterns in scientific literature. J. Am. Soc. Inf. Sci. Technol. 2006, 57, 359-377, doi:10.1002/asi.20317.

63. Chen, C.; Ibekwe-SanJuan, F.; Hou, J. The structure and dynamics of cocitation clusters: A multiple-perspective cocitation analysis. J. Am. Soc. Inf. Sci. Technol. 2010, 61, 1386-1409, doi:10.1002/asi.21309.

64. Liu, H.; Valdehuesa, K.N.G.; Ramos, K.R.M.; Nisola, G.M.; Lee, W.K.; Chung, W.J. L-arabonate and Dgalactonate production by expressing a versatile sugar dehydrogenase in metabolically engineered Escherichia coli. Bioresour. Technol. 2014, 159, 455-459, doi:10.1016/j.biortech.2014.03.056.

65. Valdehuesa, K.N.G.; Liu, H.; Ramos, K.R.M.; Park, S.J.; Nisola, G.M.; Lee, W.K.; Chung, W.J. Direct bioconversion of D-xylose to 1,2,4-butanetriol in an engineered Escherichia coli. Process Biochem. 2014, 49, 25-32, doi:10.1016/j.procbio.2013.10.002.

66. Zhang, S.; Skerker, J.M.; Rutter, C.D.; Maurer, M.J.; Arkin, A.P.; Rao, C. V. Engineering Rhodosporidium toruloides for increased lipid production. Biotechnol. Bioeng. 2016, doi:10.1002/bit.25864.

67. Oh, E.J.; Skerker, J.M.; Kim, S.R.; Wei, N.; Turner, T.L.; Maurer, M.J.; Arkin, A.P.; Jin, Y.S. Gene Amplification on 
Demand Accelerates Cellobiose Utilization in Engineered Saccharomyces cerevisiae. Appl. Environ. Microbiol. 2016, 82, 3631-3639, doi:10.1128/aem.00410-16.

68. Zhang, L.; King, E.; Luo, R.; Li, H. Development of a High-Throughput, In Vivo Selection Platform for NADPHDependent Reactions Based on Redox Balance Principles. ACS Synth. Biol. 2018, 7, 1715-1721, doi:10.1021/acssynbio.8b00179.

69. Black, W.B.; King, E.; Wang, Y.; Jenic, A.; Rowley, A.T.; Seki, K.; Luo, R.; Li, H. Engineering a Coenzyme A Detour To Expand the Product Scope and Enhance the Selectivity of the Ehrlich Pathway. ACS Synth. Biol. 2018, doi:10.1021/acssynbio.8b00358.

70. Black, W.B.; Zhang, L.Y.; Kamoku, C.; Liao, J.C.; Li, H. Rearrangement of Coenzyme A-Acylated Carbon Chain Enables Synthesis of Isobutanol via a Novel Pathway in Ralstonia eutropha. Acs Synth. Biol. 2018, 7, 794-800, doi:10.1021/acssynbio.7b00409.

71. Rydzak, T.; Garcia, D.; Stevenson, D.M.; Sladek, M.; Klingeman, D.M.; Holwerda, E.K.; Amador-Noguez, D.; Brown, S.D.; Guss, A.M. Deletion of Type I glutamine synthetase deregulates nitrogen metabolism and increases ethanol production in Clostridium thermocellum. Metab. Eng. 2017, 41, 182-191, doi:10.1016/j.ymben.2017.04.002.

72. Biswas, R.; Zheng, T.Y.; Olson, D.G.; Lynd, L.R.; Guss, A.M. Elimination of hydrogenase active site assembly blocks H-2 production and increases ethanol yield in Clostridium thermocellum. Biotechnol. Biofuels 2015, 8, 8, doi:10.1186/s13068-015-0204-4.

73. Alonso-Gutierrez, J.; Koma, D.; Hu, Q.; Yang, Y.; Chan, L.J.G.; Petzold, C.J.; Adams, P.D.; Vickers, C.E.; Nielsen, L.K.; Keasling, J.D.; et al. Toward industrial production of isoprenoids in Escherichia coli : Lessons learned from CRISPR-Cas9 based optimization of a chromosomally integrated mevalonate pathway. Biotechnol. Bioeng. 2018, 115, 1000-1013, doi:10.1002/bit.26530.

74. Brunk, E.; George, K.W.; Alonso-Gutierrez, J.; Thompson, M.; Baidoo, E.; Wang, G.; Petzold, C.J.; McCloskey, D.; Monk, J.; Yang, L.; et al. Characterizing Strain Variation in Engineered E. coli Using a Multi-Omics-Based Workflow. Cell Syst. 2016, 2, 335-346, doi:10.1016/j.cels.2016.04.004.

75. Gionata, S.; Scalcinati, G.; Partow, S.; Siewers, V.; Schalk, M.; Daviet, L.; Nielsen, J. Combined metabolic engineering of precursor and co-factor supply to increase $\alpha$-santalene production by Saccharomyces cerevisiae. Microb. Cell Fact. 2012.

76. Hammar, P.; Angermayr, S.A.; Sjostrom, S.L.; van der Meer, J.; Hellingwerf, K.J.; Hudson, E.P.; Joensson, H.N. Single-cell screening of photosynthetic growth and lactate production by cyanobacteria. Biotechnol. Biofuels 2015, 8, 8, doi:10.1186/s13068-015-0380-2.

77. Partow, S.; Siewers, V.; Daviet, L.; Schalk, M.; Nielsen, J. Reconstruction and Evaluation of the Synthetic Bacterial MEP Pathway in Saccharomyces cerevisiae. PLoS One 2012, 7, 12, doi:10.1371/journal.pone.0052498.

78. Yamada, R.; Wakita, K.; Mitsui, R.; Nishikawa, R.; Ogino, H. Efficient production of 2,3-butanediol by recombinant Saccharomyces cerevisiae through modulation of gene expression by cocktail delta-integration. Bioresour. Technol. 2017, 245, 1558-1566, doi:10.1016/j.biortech.2017.05.034.

79. Yamada, R.; Wakita, K.; Mitsui, R.; Ogino, H. Enhanced D-lactic Acid Production by Recombinant Saccharomyces cerevisiae Following Optimization of the Global Metabolic Pathway. Biotechnol. Bioeng. 2017, 114, 2075-2084, doi:10.1002/bit.26330.

80. Hasunuma, T.; Kondo, A. Development of yeast cell factories for consolidated bioprocessing of lignocellulose to bioethanol through cell surface engineering. Biotechnol. Adv. 2012, 30, 1207-1218, doi:10.1016/j.biotechadv.2011.10.011.

81. Sanda, T.; Hasunuma, T.; Matsuda, F.; Kondo, A. Repeated-batch fermentation of lignocellulosic hydrolysate to ethanol using a hybrid Saccharomyces cerevisiae strain metabolically engineered for tolerance to acetic and 
formic acids. Bioresour. Technol. 2011, doi:10.1016/j.biortech.2011.06.028.

82. Balamurugan, S.; Wang, X.; Wang, H.L.; An, C.J.; Li, H.; Li, D.W.; Yang, W.D.; Liu, J.S.; Li, H.Y. Occurrence of plastidial triacylglycerol synthesis and the potential regulatory role of AGPAT in the model diatom Phaeodactylum tricornutum. Biotechnol. Biofuels 2017, doi:10.1186/s13068-017-0786-0.

83. Yao, Y.; Lu, Y.; Peng, K.T.; Huang, T.; Niu, Y.F.; Xie, W.H.; Yang, W.D.; Liu, J.S.; Li, H.Y. Glycerol and neutral lipid production in the oleaginous marine diatom Phaeodactylum tricornutum promoted by overexpression of glycerol-3-phosphate dehydrogenase. Biotechnol. Biofuels 2014, doi:10.1186/1754-6834-7-110.

84. Ma, Y.H.; Wang, X.; Niu, Y.F.; Yang, Z.K.; Zhang, M.H.; Wang, Z.M.; Yang, W.D.; Liu, J.S.; Li, H.Y. Antisense knockdown of pyruvate dehydrogenase kinase promotes the neutral lipid accumulation in the diatom Phaeodactylum tricornutum. Microb. Cell Fact. 2014, doi:10.1186/s12934-014-0100-9.

85. Wang, M.; Liu, L.; Fan, L.; Tan, T. CRISPRi based system for enhancing 1-butanol production in engineered Klebsiella pneumoniae. Process Biochem. 2017, doi:10.1016/j.procbio.2017.02.013.

86. Alonso-Gutierrez, J.; Kim, E.M.; Batth, T.S.; Cho, N.; Hu, Q.J.; Chan, L.J.G.; Petzold, C.J.; Hinson, N.J.; Adams, P.D.; Keasling, J.D.; et al. Principal component analysis of proteomics (PCAP) as a tool to direct metabolic engineering. Metab. Eng. 2015, 28, 123-133, doi:10.1016/j.ymben.2014.11.011.

87. Kleinberg, J. Bursty and Hierarchical Structure in Streams. Data Min. Knowl. Discov. 2003, 7, 373-397, doi:https://doi.org/10.1023/A:1024940629314.

88. Peralta-Yahya, P.P.; Zhang, F.; Del Cardayre, S.B.; Keasling, J.D. Microbial engineering for the production of advanced biofuels. Nature 2012.

89. Gibson, D.G.; Young, L.; Chuang, R.Y.; Venter, J.C.; Hutchison, C.A.; Smith, H.O. Enzymatic assembly of DNA molecules up to several hundred kilobases. Nat. Methods 2009, doi:10.1038/nmeth.1318.

90. Shen, C.R.; Lan, E.I.; Dekishima, Y.; Baez, A.; Cho, K.M.; Liao, J.C. Driving Forces Enable High-Titer Anaerobic 1-Butanol Synthesis in Escherichia coli. Appl. Environ. Microbiol. 2011, doi:10.1128/aem.03034-10.

91. Connor, M.R.; Atsumi, S. Synthetic Biology Guides Biofuel Production. J. Biomed. Biotechnol. 2010, 2010, 1-9, doi:10.1155/2010/541698.

92. Tai, M.; Stephanopoulos, G. Engineering the push and pull of lipid biosynthesis in oleaginous yeast Yarrowia lipolytica for biofuel production. Metab. Eng. 2013, doi:10.1016/j.ymben.2012.08.007.

93. Dellomonaco, C.; Fava, F.; Gonzalez, R. The path to next generation biofuels: Successes and challenges in the era of synthetic biology. Microb. Cell Fact. 2010, 9, doi:10.1186/1475-2859-9-1.

94. Zhang, F.; Carothers, J.M.; Keasling, J.D. Design of a dynamic sensor-regulator system for production of chemicals and fuels derived from fatty acids. Nat. Biotechnol. 2012, doi:10.1038/nbt.2149.

95. Runguphan, W.; Keasling, J.D. Metabolic engineering of Saccharomyces cerevisiae for production of fatty acidderived biofuels and chemicals. Metab. Eng. 2014, doi:10.1016/j.ymben.2013.07.003.

96. Pandey, S. Prospects of Metagenomic Cellulases for Converting Lignocellulosic Biomass into Bio-ethanol. J. Pure Appl. Microbiol. 2017, 11, 1079-1090, doi:10.22207/JPAM.11.2.51.

97. Yu, A.; Zhao, Y.; Pang, Y.; Hu, Z.; Zhang, C.; Xiao, D.; Chang, M.W.; Leong, S.S.J. An oleaginous yeast platform for renewable 1-butanol synthesis based on a heterologous CoA-dependent pathway and an endogenous pathway. Microb. Cell Fact. 2018, 17, 166, doi:10.1186/s12934-018-1014-8.

98. Löbs, A.-K.; Schwartz, C.; Wheeldon, I. Genome and metabolic engineering in non-conventional yeasts: Current advances and applications. Synth. Syst. Biotechnol. 2017, 2, 198-207, doi:10.1016/j.synbio.2017.08.002.

99. Hagen, L.H.; Frank, J.A.; Zamanzadeh, M.; Eijsink, V.G.H.; Pope, P.B.; Horn, S.J.; Arntzen, M.Ø. Quantitative Metaproteomics Highlight the Metabolic Contributions of Uncultured Phylotypes in a Thermophilic Anaerobic Digester. Appl. Environ. Microbiol. 2017, 83, doi:10.1128/AEM.01955-16. 
100. Jayakody, L.N.; Johnson, C.W.; Whitham, J.M.; Giannone, R.J.; Black, B.A.; Cleveland, N.S.; Klingeman, D.M.; Michener, W.E.; Olstad, J.L.; Vardon, D.R.; et al. Thermochemical wastewater valorization via enhanced microbial toxicity tolerance. Energy Environ. Sci. 2018, 11, 1625-1638, doi:10.1039/C8EE00460A.

101. Chen, Y.; Wang, Y.; Chen, T.-H.; Yao, M.-D.; Xiao, W.-H.; Li, B.-Z.; Yuan, Y.-J. Identification and manipulation of a novel locus to improve cell tolerance to short-chain alcohols in Escherichia coli. J. Ind. Microbiol. Biotechnol. 2018, 45, 589-598, doi:10.1007/s10295-017-1996-y.

102. Bervoets, I.; Van Brempt, M.; Van Nerom, K.; Van Hove, B.; Maertens, J.; De Mey, M.; Charlier, D. A sigma factor toolbox for orthogonal gene expression in Escherichia coli. Nucleic Acids Res. 2018, 46, 2133-2144, doi:10.1093/nar/gky010.

103. Speda, J.; Jonsson, B.-H.; Carlsson, U.; Karlsson, M. Metaproteomics-guided selection of targeted enzymes for bioprospecting of mixed microbial communities. Biotechnol. Biofuels 2017, 10, 128, doi:10.1186/s13068-017-0815-z.

104. Hollinshead, W.; He, L.; Tang, Y.J. Biofuel production: an odyssey from metabolic engineering to fermentation scale-up. Front. Microbiol. 2014, 5, doi:10.3389/fmicb.2014.00344.

105. Toor, M.; Kumar, S.S.; Malyan, S.K.; Bishnoi, N.R.; Mathimani, T.; Rajendran, K.; Pugazhendhi, A. An overview on bioethanol production from lignocellulosic feedstocks. Chemosphere 2020, 242, 125080, doi:10.1016/j.chemosphere.2019.125080.

106. Akinosho, H.; Yee, K.; Close, D.; Ragauskas, A. The emergence of Clostridium thermocellum as a high utility candidate for consolidated bioprocessing applications. Front. Chem. 2014, 2, doi:10.3389/fchem.2014.00066.

107. Ko, J.K.; Um, Y.; Woo, H.M.; Kim, K.H.; Lee, S.-M. Ethanol production from lignocellulosic hydrolysates using engineered Saccharomyces cerevisiae harboring xylose isomerase-based pathway. Bioresour. Technol. 2016, 209, 290-296, doi:10.1016/j.biortech.2016.02.124.

108. Radecka, D.; Mukherjee, V.; Mateo, R.Q.; Stojiljkovic, M.; Foulquié-Moreno, M.R.; Thevelein, J.M. Looking beyond Saccharomyces: the potential of non-conventional yeast species for desirable traits in bioethanol fermentation. FEMS Yeast Res. 2015, 15, fov053, doi:10.1093/femsyr/fov053.

109. Zhou, S.; Du, G.; Kang, Z.; Li, J.; Chen, J.; Li, H.; Zhou, J. The application of powerful promoters to enhance gene expression in industrial microorganisms. World J. Microbiol. Biotechnol. 2017, 33, 23, doi:10.1007/s11274-016-21843.

110. Dasgupta, C.N.; Suseela, M.R.; Mandotra, S.K.; Kumar, P.; Pandey, M.K.; Toppo, K.; Lone, J.A. Dual uses of microalgal biomass: An integrative approach for biohydrogen and biodiesel production. Appl. Energy 2015, 146, 202-208, doi:10.1016/j.apenergy.2015.01.070.

111. Park, J.M.; Rathnasingh, C.; Song, H. Metabolic engineering of Klebsiella pneumoniae based on in silico analysis and its pilot-scale application for 1,3-propanediol and 2,3-butanediol co-production. J. Ind. Microbiol. Biotechnol. 2017, 44, 431-441, doi:10.1007/s10295-016-1898-4.

112. Liu, C.; Zhang, K.; Cao, W.; Zhang, G.; Chen, G.; Yang, H.; Wang, Q.; Liu, H.; Xian, M.; Zhang, H. Genome mining of 2-phenylethanol biosynthetic genes from Enterobacter sp. CGMCC 5087 and heterologous overproduction in Escherichia coli. Biotechnol. Biofuels 2018, 11, 305, doi:10.1186/s13068-018-1297-3.

113. Hwang, H.J.; Lee, S.Y.; Lee, P.C. Engineering and application of synthetic nar promoter for fine-tuning the expression of metabolic pathway genes in Escherichia coli. Biotechnol. Biofuels 2018, 11, 103, doi:10.1186/s13068018-1104-1.

114. Buhaescu, I.; Izzedine, H. Mevalonate pathway: A review of clinical and therapeutical implications. Clin. Biochem. 2007, 40, 575-584, doi:10.1016/j.clinbiochem.2007.03.016.

115. Guo, X.-W.; Zhang, Y.; Li, L.-L.; Guan, X.-Y.; Guo, J.; Wu, D.-G.; Chen, Y.-F.; Xiao, D.-G. Improved xylose tolerance and 2,3-butanediol production of Klebsiella pneumoniae by directed evolution of rpoD and the 
mechanisms revealed by transcriptomics. Biotechnol. Biofuels 2018, 11, 307, doi:10.1186/s13068-018-1312-8.

116. Rhie, M.N.; Kim, H.T.; Jo, S.Y.; Chu, L.L.; Baritugo, K.-A.; Baylon, M.G.; Lee, J.; Na, J.-G.; Kim, L.H.; Kim, T.W.; et al. Recent Advances in the Metabolic Engineering of Klebsiella pneumoniae: A Potential Platform Microorganism for Biorefineries. Biotechnol. Bioprocess Eng. 2019, 24, 48-64, doi:10.1007/s12257-018-0346-x.

117. Allen, R.S.; Tilbrook, K.; Warden, A.C.; Campbell, P.C.; Rolland, V.; Singh, S.P.; Wood, C.C. Expression of 16 Nitrogenase Proteins within the Plant Mitochondrial Matrix. Front. Plant Sci. 2017, 8, doi:10.3389/fpls.2017.00287.

118. Veerabadhran, M.; Natesan, S.; MubarakAli, D.; Xu, S.; Yang, F. Using different cultivation strategies and methods for the production of microalgal biomass as a raw material for the generation of bioproducts. Chemosphere 2021, 285, 131436, doi:10.1016/j.chemosphere.2021.131436.

119. Maeda, Y.; Yoshino, T.; Matsunaga, T.; Matsumoto, M.; Tanaka, T. Marine microalgae for production of biofuels and chemicals. Curr. Opin. Biotechnol. 2018, 50, 111-120, doi:10.1016/j.copbio.2017.11.018.

120. Si, T.; Zhao, H. A brief overview of synthetic biology research programs and roadmap studies in the United States. Synth. Syst. Biotechnol. 2016, 1, 258-264, doi:10.1016/j.synbio.2016.08.003.

121. Katz, L.; Chen, Y.Y.; Gonzalez, R.; Peterson, T.C.; Zhao, H.; Baltz, R.H. Synthetic biology advances and applications in the biotechnology industry: a perspective. J. Ind. Microbiol. Biotechnol. 2018, 45, 449-461, doi:10.1007/s10295-018-2056-y.

122. Adler-Agnon, Z.; Leu, S.; Zarka, A.; Boussiba, S.; Khozin-Goldberg, I. Novel promoters for constitutive and inducible expression of transgenes in the diatom Phaeodactylum tricornutum under varied nitrate availability. J. Appl. Phycol. 2018, 30, 2763-2772, doi:10.1007/s10811-017-1335-8.

123. Keasling, J.D. Synthetic biology and the development of tools for metabolic engineering. Metab. Eng. 2012, 14, 189-195, doi:10.1016/j.ymben.2012.01.004.

124. Kelwick, R.; MacDonald, J.T.; Webb, A.J.; Freemont, P. Developments in the Tools and Methodologies of Synthetic Biology. Front. Bioeng. Biotechnol. 2014, 2, doi:10.3389/fbioe.2014.00060.

125. Paddon, C.J.; Keasling, J.D. Semi-synthetic artemisinin: a model for the use of synthetic biology in pharmaceutical development. Nat. Rev. Microbiol. 2014, 12, 355-367, doi:10.1038/nrmicro3240.

126. Zou, X.; Wang, L.; Li, Z.; Luo, J.; Wang, Y.; Deng, Z.; Du, S.; Chen, S. Genome Engineering and Modification Toward Synthetic Biology for the Production of Antibiotics. Med. Res. Rev. 2018, 38, 229-260, doi:10.1002/med.21439.

127. Sengupta, A.; Pakrasi, H.B.; Wangikar, P.P. Recent advances in synthetic biology of cyanobacteria. Appl. Microbiol. Biotechnol. 2018, 102, 5457-5471, doi:10.1007/s00253-018-9046-x.

128. Smanski, M.J.; Zhou, H.; Claesen, J.; Shen, B.; Fischbach, M.A.; Voigt, C.A. Synthetic biology to access and expand nature's chemical diversity. Nat. Rev. Microbiol. 2016, 14, 135-149, doi:10.1038/nrmicro.2015.24.

129. Flores Bueso, Y.; Tangney, M. Synthetic Biology in the Driving Seat of the Bioeconomy. Trends Biotechnol. 2017, 35, 373-378, doi:10.1016/j.tibtech.2017.02.002.

130. Gronvall, G.K. US Competitiveness in Synthetic Biology. Heal. Secur. 2015, 13, 378-389, doi:10.1089/hs.2015.0046.

131. Darvishi, F.; Ariana, M.; Marella, E.R.; Borodina, I. Advances in synthetic biology of oleaginous yeast Yarrowia lipolytica for producing non-native chemicals. Appl. Microbiol. Biotechnol. 2018, 102, 5925-5938, doi:10.1007/s00253-018-9099-x.

132. Xu, G.; Wu, A.; Xiao, L.; Han, R.; Ni, Y. Enhancing butanol tolerance of Escherichia coli reveals hydrophobic interaction of multi-tasking chaperone SecB. Biotechnol. Biofuels 2019, 12, 164, doi:10.1186/s13068-019-1507-7.

133. Cheng, F.; Tang, X.-L.; Kardashliev, T. Transcription Factor-Based Biosensors in High-Throughput Screening: Advances and Applications. Biotechnol. J. 2018, 13, 1700648, doi:10.1002/biot.201700648.

134. Chen, Y.; Banerjee, D.; Mukhopadhyay, A.; Petzold, C.J. Systems and synthetic biology tools for advanced 
bioproduction hosts. Curr. Opin. Biotechnol. 2020, 64, 101-109, doi:10.1016/j.copbio.2019.12.007.

135. Schwartz, C.M.; Hussain, M.S.; Blenner, M.; Wheeldon, I. Synthetic RNA Polymerase III Promoters Facilitate High-Efficiency CRISPR-Cas9-Mediated Genome Editing in Yarrowia lipolytica. ACS Synth. Biol. 2016, 5, 356359, doi:10.1021/acssynbio.5b00162.

136. Gao, D.; Smith, S.; Spagnuolo, M.; Rodriguez, G.; Blenner, M. Dual CRISPR-Cas9 Cleavage Mediated Gene Excision and Targeted Integration in Yarrowia lipolytica. Biotechnol. J. 2018, 13, 1700590, doi:10.1002/biot.201700590.

137. Santos-Merino, M.; Garcillán-Barcia, M.P.; de la Cruz, F. Engineering the fatty acid synthesis pathway in Synechococcus elongatus PCC 7942 improves omega-3 fatty acid production. Biotechnol. Biofuels 2018, 11, 239, doi:10.1186/s13068-018-1243-4.

138. Maheshwari, N. V. Agro-industrial Lignocellulosic Waste: An Alternative to Unravel the Future Bioenergy. In Biofuels: Greenhouse Gas Mitigation and Global Warming; Springer India: New Delhi, 2018; pp. 291-305.

139. González-García, S.; Gullón, P.; Gullón, B. Bio-compounds Production from Agri-food Wastes Under a Biorefinery Approach: Exploring Environmental and Social Sustainability. In; 2019; pp. 25-53.

140. Siddiqui, M.R.; Miranda, A.; Mouradov, A. Microalgae as Bio-Converters of Wastewater into Biofuel and Food. In Water Scarcity and Ways to Reduce the Impact; Springer International Publishing: Cham, 2019; pp. 75-94.

141. Ko, J.K.; Lee, S.-M. Advances in cellulosic conversion to fuels: engineering yeasts for cellulosic bioethanol and biodiesel production. Curr. Opin. Biotechnol. 2018, 50, 72-80, doi:10.1016/j.copbio.2017.11.007.

142. Kim, N.M.; Sinnott, R.W.; Sandoval, N.R. Transcription factor-based biosensors and inducible systems in nonmodel bacteria: current progress and future directions. Curr. Opin. Biotechnol. 2020, 64, 39-46, doi:10.1016/j.copbio.2019.09.009.

143. Shi, T.-Q.; Huang, H.; Kerkhoven, E.J.; Ji, X.-J. Advancing metabolic engineering of Yarrowia lipolytica using the CRISPR/Cas system. Appl. Microbiol. Biotechnol. 2018, 102, 9541-9548, doi:10.1007/s00253-018-9366-x.

144. Gujjala, L.K.S.; Kumar, S.P.J.; Talukdar, B.; Dash, A.; Kumar, S.; Sherpa, K.C.; Banerjee, R. Biodiesel from oleaginous microbes: opportunities and challenges. Biofuels 2019, 10, 45-59, doi:10.1080/17597269.2017.1402587.

145. Albers, S.C.; Berklund, A.M.; Graff, G.D. The rise and fall of innovation in biofuels. Nat. Biotechnol. 2016, 34, 814821, doi:10.1038/nbt.3644.

146. Goold, H.; Wright, P.; Hailstones, D. Emerging Opportunities for Synthetic Biology in Agriculture. Genes (Basel). 2018, 9, 341, doi:10.3390/genes9070341.

147. Pixley, K. V.; Falck-Zepeda, J.B.; Giller, K.E.; Glenna, L.L.; Gould, F.; Mallory-Smith, C.A.; Stelly, D.M.; Stewart, C.N. Genome Editing, Gene Drives, and Synthetic Biology: Will They Contribute to Disease-Resistant Crops, and Who Will Benefit? Annu. Rev. Phytopathol. 2019, 57, 165-188, doi:10.1146/annurev-phyto-080417-045954.

148. Liu, G.; Gilding, E.K.; Kerr, E.D.; Schulz, B.L.; Tabet, B.; Hamaker, B.R.; Godwin, I.D. Increasing protein content and digestibility in sorghum grain with a synthetic biology approach. J. Cereal Sci. 2019, 85, 27-34, doi:10.1016/j.jcs.2018.11.001.

149. Wurtzel, E.T.; Vickers, C.E.; Hanson, A.D.; Millar, A.H.; Cooper, M.; Voss-Fels, K.P.; Nikel, P.I.; Erb, T.J. Revolutionizing agriculture with synthetic biology. Nat. Plants 2019, 5, 1207-1210, doi:10.1038/s41477-019-05390 .

150. Tyagi, A.; Kumar, A.; Aparna, S. V.; Mallappa, R.H.; Grover, S.; Batish, V.K. Synthetic Biology: Applications in the Food Sector. Crit. Rev. Food Sci. Nutr. 2016, 56, 1777-1789, doi:10.1080/10408398.2013.782534.

151. Mortimer, J.C. Plant synthetic biology could drive a revolution in biofuels and medicine. Exp. Biol. Med. 2019, 244, 323-331, doi:10.1177/1535370218793890.

152. Sekurova, O.N.; Schneider, O.; Zotchev, S.B. Novel bioactive natural products from bacteria via bioprospecting, 
genome mining and metabolic engineering. Microb. Biotechnol. 2019, 12, 828-844, doi:10.1111/1751-7915.13398.

153. Aguilar, A.; Twardowski, T.; Wohlgemuth, R. Bioeconomy for Sustainable Development. Biotechnol. J. 2019, 14, 1800638, doi:10.1002/biot.201800638.

154. Bengyella, L.; Iftikhar, S.; Nawaz, K.; Fonmboh, D.J.; Yekwa, E.L.; Jones, R.C.; Njanu, Y.M.T.; Roy, P. Biotechnological application of endophytic filamentous bipolaris and curvularia: a review on bioeconomy impact. World J. Microbiol. Biotechnol. 2019, 35, 69, doi:10.1007/s11274-019-2644-7.

155. Zabed, H.M.; Akter, S.; Yun, J.; Zhang, G.; Awad, F.N.; Qi, X.; Sahu, J.N. Recent advances in biological pretreatment of microalgae and lignocellulosic biomass for biofuel production. Renew. Sustain. Energy Rev. 2019, 105, 105-128, doi:10.1016/j.rser.2019.01.048.

156. Havlík, P.; Schneider, U.A.; Schmid, E.; Böttcher, H.; Fritz, S.; Skalský, R.; Aoki, K.; Cara, S. De; Kindermann, G.; Kraxner, F.; et al. Global land-use implications of first and second generation biofuel targets. Energy Policy 2011, 39, 5690-5702, doi:10.1016/j.enpol.2010.03.030.

157. Wallington, T.J.; Anderson, J.E.; De Kleine, R.D.; Kim, H.C.; Maas, H.; Brandt, A.R.; Keoleian, G.A. When Comparing Alternative Fuel-Vehicle Systems, Life Cycle Assessment Studies Should Consider Trends in Oil Production. J. Ind. Ecol. 2017, 21, 244-248, doi:10.1111/jiec.12418.

158. Synnestvedt, M.B.; Chen, C.; Holmes, J.H. CiteSpace II: visualization and knowledge discovery in bibliographic databases. In Proceedings of the AMIA Annual Symposium Proceedings; 2005; pp. 724-728.

159. Yu, X.; Zhang, B. Obtaining advantages from technology revolution: A patent roadmap for competition analysis and strategy planning. Technol. Forecast. Soc. Change 2019, 145, 273-283, doi:10.1016/j.techfore.2017.10.008.

160. Daim, T.; Lai, K.K.; Yalcin, H.; Alsoubie, F.; Kumar, V. Forecasting technological positioning through technology knowledge redundancy: Patent citation analysis of IoT, cybersecurity, and Blockchain. Technol. Forecast. Soc. Change 2020, 161, 120329, doi:10.1016/j.techfore.2020.120329.

161. Huang, D.; Jin, X.; Coghlan, A. Advances in consumer innovation resistance research: A review and research agenda. Technol. Forecast. Soc. Change 2021, 166, 120594, doi:10.1016/j.techfore.2021.120594.

162. Mogoutov, A.; Kahane, B. Data search strategy for science and technology emergence: A scalable and evolutionary query for nanotechnology tracking. Res. Policy 2007, 36, 893-903, doi:10.1016/j.respol.2007.02.005.

163. Jarboe, L.R.; Zhang, X.; Wang, X.; Moore, J.C.; Shanmugam, K.T.; Ingram, L.O. Metabolic Engineering for Production of Biorenewable Fuels and Chemicals: Contributions of Synthetic Biology. J. Biomed. Biotechnol. 2010, 2010, 1-18, doi:10.1155/2010/761042.

164. Nielsen, J.; Keasling, J.D. Synergies between synthetic biology and metabolic engineering. Nat. Biotechnol. 2011, 29, 693-695, doi:10.1038/nbt.1937.

165. Jullesson, D.; David, F.; Pfleger, B.; Nielsen, J. Impact of synthetic biology and metabolic engineering on industrial production of fine chemicals. Biotechnol. Adv. 2015, 33, 1395-1402, doi:10.1016/j.biotechadv.2015.02.011.

166. Raimbault, B.; Cointet, J.-P.; Joly, P.-B. Mapping the Emergence of Synthetic Biology. PLoS One 2016, 11, e0161522, doi:10.1371/journal.pone.0161522.

167. Yeung, A.W.K.; Tzvetkov, N.T.; Gupta, V.K.; Gupta, S.C.; Orive, G.; Bonn, G.K.; Fiebich, B.; Bishayee, A.; Efferth, T.; Xiao, J.; et al. Current research in biotechnology: Exploring the biotech forefront. Curr. Res. Biotechnol. 2019, 1, 34-40, doi:10.1016/j.crbiot.2019.08.003.

168. Hou, J.; Yang, X.; Chen, C. Emerging trends and new developments in information science: a document cocitation analysis (2009-2016). Scientometrics 2018, 115, 869-892, doi:10.1007/s11192-018-2695-9.

169. Guangfen, Y.; Dongke, Z. An Analysis Based on Citespace III Knowledge Maps of Chinese Vocational Education Research. Chinese Educ. Soc. 2017, 50, 499-519, doi:10.1080/10611932.2017.1408304.

170. Ma, S.; Yu, X.; Chen, Q. Hotspots Analysis and Its Applications in Vocational Education with CiteSpace. In 
Proceedings of the 2019 10th International Conference on Information Technology in Medicine and Education (ITME); IEEE, 2019; pp. 394-398.

171. Rousseeuw, P.J. Silhouettes: A graphical aid to the interpretation and validation of cluster analysis. J. Comput. Appl. Math. 1987, 20, 53-65, doi:10.1016/0377-0427(87)90125-7. 